\title{
La situación de los centros residenciales para personas mayores en Gipuzkoa ${ }^{1}$
}

\section{SIIS Centro de Documentación y Estudios}

\author{
Fundación Eguía-Careaga \\ <estudios@siis.net>
}

\begin{abstract}
Artikulu honetan laburbiltzen da Gipuzkoako biztanle adinduentzat bideratutako egoitza-zentroen egoera ezagutzeko SIIS Dokumentazio eta Ikerketa Zentroak buruturiko txostenaren emaitzak. Lan hori kokatzen da Gipuzkoako Foru Aldundiko Gizarte Politikako Departamenduak egoitzazentroen sarearen oinarrizko alderdien inguruan abian jarritako gogoeta-prozesuan. Txostenaren emaitzek erakusten dituzte lurraldeko egoitzetako arreta-ereduaren alderdi indartsu eta ahuldadeak. Lehenengo horien artetik nabarmentzen da ardura publikoko plazen kopuru altua, bertan lan egiten dutenen laneko baldintzen hobekuntza-prozesua, sektoreak duen enplegua sortzeko gaitasun altua, eta zentro horietan guztietan eskaintzen den arretaren kalitatea. Ahuleziei dagokienez, nabarmendu daiteke arretarako estalduraren murrizketa progresiboa (eta hori gertatzen da eskuragarri jartzen diren plaza kopuruak motel hazten direlako); balizko erabiltzaileen artean iraunkorra gertatzen den aurreiritzi bat, izan ere, egoitza batean sartzea ez baita desiragarritzat hartzen; izaera pertsonalizatuagoa duen arretaeredu baten alde egitea eta eredu hori erabiltzaile diren biztanleen bizi-kalitatearen alde orientatzea; eta sistemaren iraunkortasun ekonomikoa. Hori lortzeko, premiazkoa da bai finantziazio publikoaz bai kostu unitario eta erabiltzaile diren biztanleen partaidetza ekonomikoaz gogoeta burutzea.
\end{abstract}

\section{GAKO-HITZAK:}

Egoitzak, pertsona adinduak, mendetasuna, gizarte zerbitzuak, gastu publikoa.
Este artículo sintetiza los resultados del informe sobre la situación de los centros residenciales guipuzcoanos destinados a personas mayores, realizado por el SIIS Centro de Documentación y Estudios en el marco del proceso de reflexión sobre los aspectos básicos de la red de centros residenciales puesto en marcha por el Departamento de Políticas Sociales de la Diputación Foral de Gipuzkoa. Los datos del informe ponen de manifiesto tanto las fortalezas como las debilidades del actual modelo de atención residencial en el territorio. Entre las primeras, destaca la elevada dotación de plazas de responsabilidad pública, el proceso de mejora en las condiciones laborales del personal ocupado, la elevada capacidad de generación de empleo del sector, y la calidad de la atención que se presta en el conjunto de los centros. Entre las debilidades, cabe señalar la progresiva reducción en las coberturas de atención (que se deriva del lento crecimiento en el número de plazas disponibles); la persistencia de cierto prejuicio por parte de las personas potencialmente usuarias, que consideran el ingreso en residencia como una opción poco apetecible; la necesidad de seguir avanzando en un modelo de atención más personalizado y más orientado a la calidad de vida de las personas usuarias; y la sostenibilidad económica del sistema, que requiere reflexionar tanto sobre la financiación pública como sobre la evolución de los costes unitarios y la participación económica de las personas usuarias.

\section{Palabras Clave:}

Residencias, personas mayores, dependencia, servicios sociales, gasto público.

${ }^{1}$ Este artículo sintetiza el informe La situación de los centros residenciales para personas mayores en Gipuzkoa (2016), elaborado por el SIIS Centro de Documentación y Estudios para el Departamento de Política Social de la Diputación Foral de Gipuzkoa. 


\section{Introducción}

Este artículo sintetiza los resultados del informe $L a$ situación de los centros residenciales para personas mayores en Gipuzkoa, elaborado por el SIIS Centro de Documentación y Estudios a instancias del Departamento de Políticas Sociales del Gobierno Vasco. Su objetivo es conocer la situación de la atención residencial en el territorio guipuzcoano, tanto en lo que se refiere a los aspectos directamente relacionados con la gestión del servicio, como en aquellos relacionados con la calidad de la atención que se presta a las personas usuarias. Para ello, además de examinar los datos disponibles sobre la atención residencial, se recoge también la visión de algunos agentes implicados en la prestación del servicio respecto a las fortalezas y debilidades del modelo de atención guipuzcoano.

Desde el punto de vista metodológico, el informe se basa tanto en los datos cuantitativos disponibles como en el análisis cualitativo de la percepción que los agentes implicados en la gestión y la provisión del servicio tienen en relación con su situación actual. Más concretamente:

- En lo que se refiere a la perspectiva cuantitativa, se han utilizado los datos que ofrecen las fuentes estadísticas habitualmente utilizadas en nuestro entorno en relación con los servicios sociales. Las fuentes utilizadas han sido, básicamente, la Estadística de Servicios Sociales que elabora el Órgano Estadístico de Servicios Sociales del Departamento de Empleo y Políticas Sociales del Gobierno Vasco², así la información recogida en el Observatorio Social de Gipuzkoa (Behagi) y la documentación que publica el propio Departamento de Políticas Sociales de la Diputación en sus memorias y catálogos de servicios. También se utilizan otras fuentes externas (OCDE, CSIC), fundamentalmente para comparar la situación en Gipuzkoa con la que existe en otras comunidades autónomas u otros países de nuestro entorno.

- En cuanto a la perspectiva cualitativa, se ha contado con la colaboración de casi treinta personas, consideradas como expertas o informantes clave, que trabajan en centros residenciales públicos y privados así como en otras entidades (organizaciones del tercer sector, Administración, centrales sindicales y asociaciones empresariales). Se ha recogido, mediante un cuestionario y una serie de grupos de discusión, la visión -no siempre coincidente-sobre el perfil de las personas usuarias, la evolución en la demanda de atención, los servicios complementarios a

2 Pese a que los datos de esa encuesta no tienen la actualización deseable, la ventaja de utilizar esta fuente consiste en que permite comparar, sobre la misma base metodológica, los datos de Gipuzkoa con los de los otros dos territorios de la CAPV, así como analizar la evolución de los principales indicadores relacionados con los centros residenciales desde mediados de los años noventa hasta la actualidad. las residencias, la calidad de la atención que se presta en las residencias, las relaciones entre la Administración pública y las entidades privadas que colaboran en la prestación del servicio, las condiciones laborales del personal ocupado o las cuestiones relacionadas con la financiación del servicio, incluyendo los aspectos referidos a las tarifas de concertación y la participación económica de las personas usuarias en la financiación de esos centros.

La estructura de este artículo se corresponde con la del propio informe. En primer lugar, se presentan los datos disponibles sobre la cobertura total de la red de atención residencial para personas mayores, prestando especial atención a la red foral de atención, además de los datos disponibles sobre la demanda de atención y, desde una perspectiva más cualitativa, sobre los cambios registrados en el perfil de las personas usuarias y en sus necesidades. En segundo lugar, se analiza la situación del personal ocupado en el sector residencial y sus condiciones laborales. En el tercer apartado, se examinan algunos aspectos económicos, como el gasto en centros residenciales, el coste/plaza, la aportación económica de las personas usuarias y el modelo de gestión y financiación. A partir de toda esa información, el último apartado recoge la valoración que los/as autores/as del informe hacen sobre las fortalezas y debilidades de la actual red de atención a personas mayores en Gipuzkoa.

\section{Cobertura de la red, titularidad de los centros y demanda de plazas}

Según los datos que proporciona la última edición de la Estadística de Servicios Sociales, en el territorio histórico de Gipuzkoa existen en 2013 un total de 127 centros que ofrecen atención residencial a personas mayores, de los cuales el $68,5 \%$ son de titularidad pública. Sin embargo, la mitad de las plazas de los centros de atención residencial están ubicadas en centros de titularidad privada. Debido al mayor tamaño medio de los centros de titularidad privada, de las 5.904 plazas existentes en Gipuzkoa, el 50,2 \% se ubican en centros de titularidad pública, mientras que el $49,8 \%$ restante lo hacen en centros de titularidad privada. Es importante destacar, en cualquier caso, que las dos terceras partes de las plazas disponibles en centros de titularidad privada están concertadas con las Administraciones públicas, sobre todo con la Diputación Foral de Gipuzkoa. Sólo 726 de las 2.938 plazas en centros de titularidad privada son plazas privadas no concertadas, lo cual representa apenas un $12 \%$ de la oferta residencial total en Gipuzkoa.

Al margen de la titularidad de los centros, si la atención se centra exclusivamente en las plazas que cuentan con financiación pública, los datos para Gipuzkoa ponen de relieve que, de las 5.904 plazas disponibles, 5.178 se encuentran o bien concertadas (2.212 plazas) o bien ubicadas en centros de titularidad pública (2.966 plazas). 


\subsection{La cobertura conjunta}

En 2013, los centros de atención residencial a personas mayores disponen de 5.904 plazas, la mayoría de ellas, en centros residenciales ( $91 \%$ ) y el resto en apartamentos tutelados (5\%) y viviendas comunitarias (4\%) [Gráfico 1]. En términos generales, y sin tener en cuenta criterios como el tipo de servicio residencial, la titularidad de los centros o su financiación, la cobertura conjunta de la atención residencial en Gipuzkoa asciende a 4,104 plazas por cada 100 habitantes mayores de 65 años 3 . Si del total de plazas residenciales disponibles (5.904 plazas) se detraen aquellas enteramente privadas, es decir, no financiadas por ninguna Administración pública (726 plazas), la cobertura resultante sería de 3,599 por cada 100 habitantes mayores de 65 años.

Desde el punto de vista comparativo, se observa que en 2013 Gipuzkoa es -en términos relativos- el territorio histórico con una menor oferta residencial dirigida a personas mayores. En efecto, tanto Álava (4,78 plazas por cada 100 personas de 65 y más años) como Bizkaia $(4,63)$ disponen de una cobertura total mayor que la que resulta para Gipuzkoa $(4,10)$. Sin embargo, es el territorio con una mayor cobertura pública de estos servicios. Ello se debe a que, mientras que en Gipuzkoa la mayor parte de la oferta de plazas es de responsabilidad pública - plazas de titularidad pública o concertada-, en Bizkaia y en Álava el porcentaje que representan las plazas privadas no concertadas es relativamente elevado.
Desde el punto de vista evolutivo, cabe señalar también que tras años de crecimiento sostenido, la creación de nuevas plazas residenciales se ralentiza y prácticamente se estanca a partir de 2009 , lo que supone que las tasas de cobertura se van reduciendo de forma progresiva. En ese sentido, la cobertura que la Estadística de Servicios Sociales y Acción Social registra en Gipuzkoa para 2014 es prácticamente la misma que existía en $\mathbf{2 0 0 5}$, cuando existían casi mil plazas residenciales menos en el territorio. De esta manera, se pone de manifiesto la existencia de dos periodos muy diferentes en lo que se refiere a la evolución de la cobertura residencial en Gipuzkoa.

El crecimiento observado durante el periodo 20022009 fue progresivo -el ritmo de crecimiento en estos siete años supuso, de media, la creación de 245 plazas nuevas al año-y se debió casi en exclusiva al sector privado: de las 1.207 plazas creadas en este periodo, sólo un $9 \%$ correspondió a centros de titularidad pública. En los últimos años, se observa la tendencia opuesta. Entre 2013 y 2010 , el sector privado oferta 443 plazas menos, mientras que el público incrementa su oferta residencial en 407 plazas. Como consecuencia, la cobertura pública se ha mantenido estable (con una ligera tendencia al alza) desde 2007, mientras que la cobertura de plazas privadas ha descendido ligeramente.
Distribución de las plazas (\%)

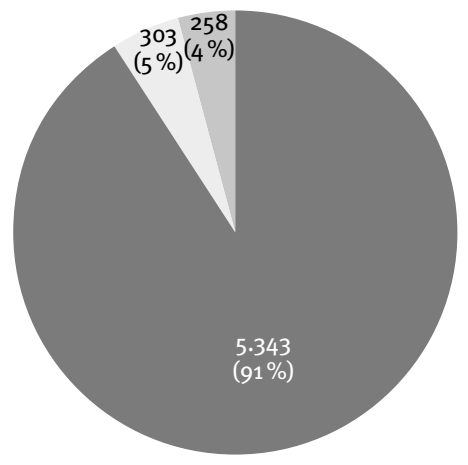

Centros residenciales

Apartamentos tutelados

Viviendas comunitarias

\section{Cobertura}

(plazas por cada 100 personas de 65 y más años)

\section{5}

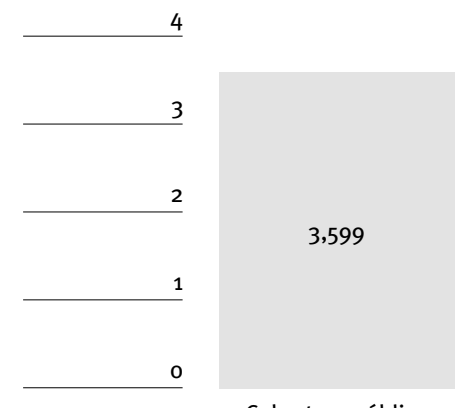

Cobertura pública

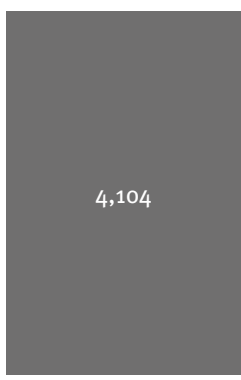

Cobertura total

Fuente: Estadística de Servicios Sociales y Acción Social 2013 (Órgano Estadístico Específico del Departamento de Empleo y Políticas Sociales del Gobierno Vasco).

${ }^{3}$ La cobertura resultante para 2014, a partir del avance de datos de la Estadística de Servicios Sociales y Acción Social, indica una cobertura ligeramente inferior - del 4,06\%- en la medida en que el crecimiento en el número de plazas ha sido proporcionalmente inferior al de la población mayor de 65 años. 
6



Álava

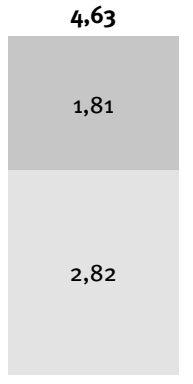

Bizkaia

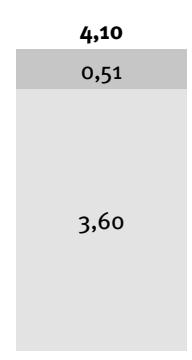

Gipuzkoa

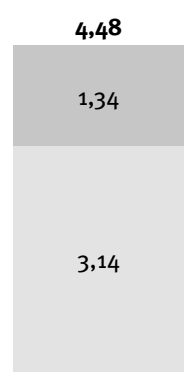

CAPV

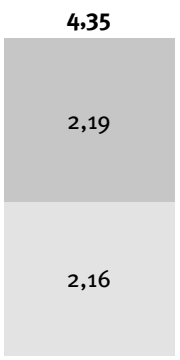

España (2015)

Pública (plazas públicas y privadas concertadas)

Privada (plazas privadas no concertadas)

Fuente: Estadística de Servicios Sociales y Acción Social 2013 (Órgano Estadístico Específico del Departamento de Empleo y Políticas Sociales del Gobierno Vasco).

Gráfico 3. Evolución de la cobertura de los centros que ofrecen atención residencial a personas mayores, por territorio histórico. CAPV, 2000-2014 (\%)

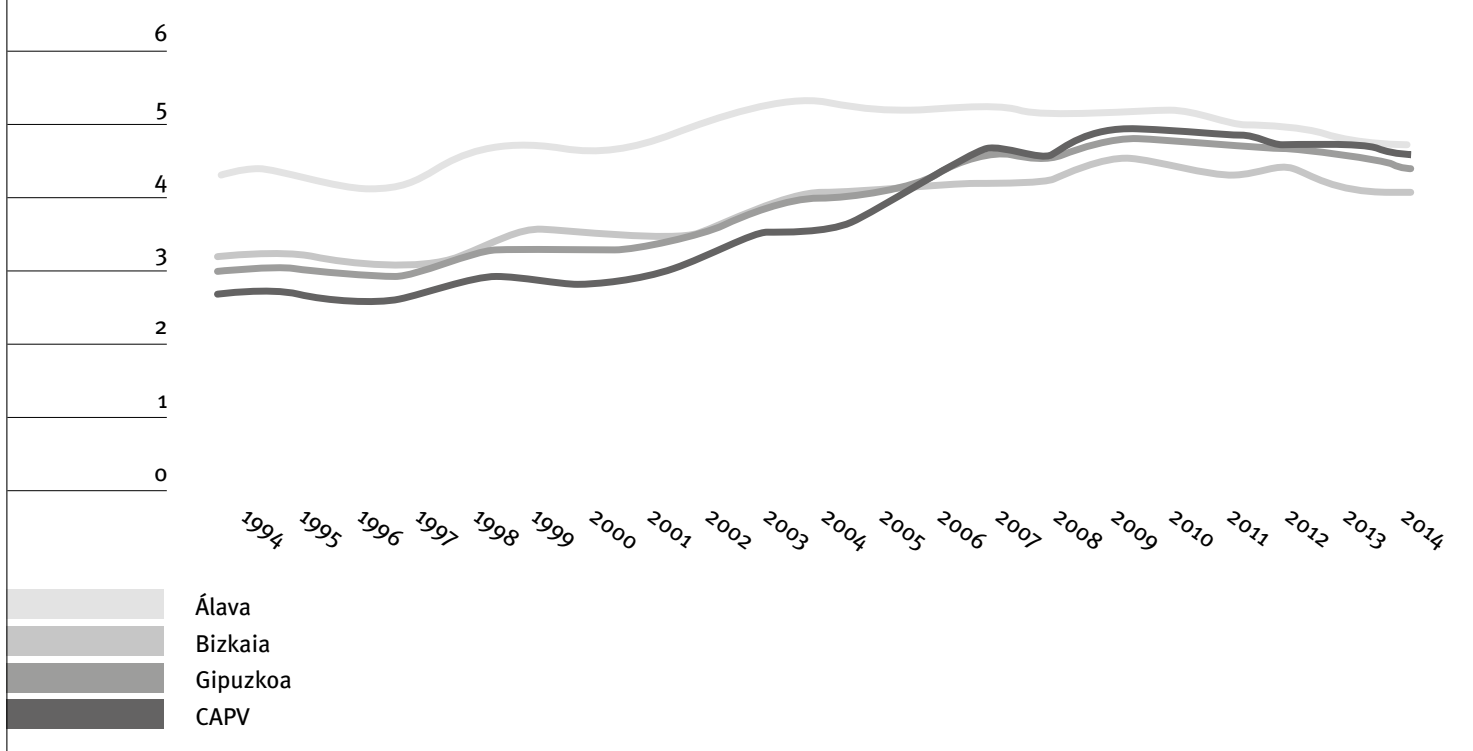

Nota: Las coberturas están calculadas sobre la población de 65 y más años de cada territorio.

Fuentes: Elaboración propia a partir de la Estadística de Servicios Sociales y Acción Social (Órgano Estadístico Específico del Departamento de Empleo y Políticas Sociales del Gobierno Vasco) y del padrón (INE).

\subsection{La red foral de atención}

Una vez analizada la información sobre el conjunto de las plazas residenciales que existen en Gipuzkoa -es decir, tanto las de responsabilidad pública como las privadas, y tanto las ubicadas en centros residenciales como las ubicadas en viviendas 0 apartamentos-, se analizan los datos disponibles en relación con las plazas disponibles en centros residenciales de responsabilidad foral para personas mayores dependientes, es decir, la dotación conjunta que suponen las plazas que son titularidad de la Diputación Foral de Gipuzkoa y las que están directamente concertadas por esta institución, independientemente de que su gestión corresponda a otra entidad pública (Ayuntamientos), a una entidad sin fin de lucro o a una entidad mercantil, con fin de lucro. 
A 31 de diciembre de 2015, la Diputación cuenta con una red de plazas residenciales para personas mayores dependientes que asciende a 4.489 plazas. Estas plazas representan el $83,3 \%$ de todas las plazas autorizadas en residencias (5.389 plazas) y en torno a un $74 \%$ de todas las plazas en servicios sociales residenciales para personas mayores ${ }^{4}$. Es importante señalar por otra parte que el $97 \%$ de las plazas municipales, y el $80 \%$ de las plazas privadas, están concertadas con la Administración foral.

Las principales características de la red de atención residencial foral a las personas mayores dependientes son, en cuanto a la financiación, la titularidad y la gestión de las plazas, las siguientes:

- Cuatro de cada diez centros de la red foral de atención residencial a personas mayores son de titularidad pública. La red foral de plazas actual está conformada por un total de 62 centros, de los cuales 36 son de titularidad privada 5 y son 26 públicos (el $42 \%$ ). Entre las residencias de titularidad pública, 10 son centros propios forales y 16 son residencias municipales, con las que la Diputación concierta un total de 1.297 plazas. En total los centros públicos ofrecen el $47,5 \%$ de las plazas forales existentes.

- Algo más de 8 de cada 10 plazas forales son concertadas. Los centros concertados, 52 en total, disponen de 4.318 plazas autorizadas. De todas ellas, estos centros conciertan con la Diputación Foral de Gipuzkoa casi el 85\% (3.652 plazas). Estas plazas representan el $81 \%$ de la red de plazas forales. Aunque la mayoría de estas plazas (2.355), el $64 \%$, se encuentran en residencias privadas, el $36 \%$ están ubicadas en centros residenciales de titularidad municipal.
- Entre los centros propios forales, la gestión indirecta es la predominante. De los diez centros propios de los que dispone la Diputación, sólo uno de ellos - la residencia Egogain, de Eibar-es de gestión directa. De los nueve restantes, seis son de gestión indirecta y tres se encuentran en régimen de concesión administrativa. En general, de las 837 plazas forales ${ }^{6}$ con las que cuentan estos centros, sólo 142 (el 17\%) corresponden a plazas ubicadas en centros de gestión directa.

- La fórmula de gestión mayoritaria entre los centros municipales es la gestión directa. Al menos hasta la constitución de Kabia, de los 16 centros residenciales municipales con los que la Diputación concertaba plazas, 11 contaban con la fórmula de gestión directa ( $81 \%$ de las plazas), mientras que cinco eran gestionados de manera indirecta ( $19 \%$ de las plazas).

Durante los últimos años, la red de plazas forales en residencias para personas mayores en Gipuzkoa ha experimentado un ligero crecimiento. Entre 2008 y 2015, el número de plazas residenciales autorizadas por la Diputación se ha incrementado en un 6,9\%, pasando de 5.041 plazas a 5.389. La misma evolución han experimentado las plazas con financiación foral, que en estos ocho años se han visto incrementadas en 302 plazas, pasando de 4.187 a 4.489 (lo que supone un incremento del 7,2\%). A pesar de que el número de plazas forales se ha incrementado en un $6,7 \%$ entre 2008 y 2015 , si la cobertura de estas plazas se calcula considerando la población de 65 y más años, se observa una tendencia decreciente, ya que en este periodo la población mayor ha aumentado en mayor medida (17\%).

Gráfico 4. Evolución de las plazas y la cobertura foral para personas mayores. Gipuzkoa, 2008-2015

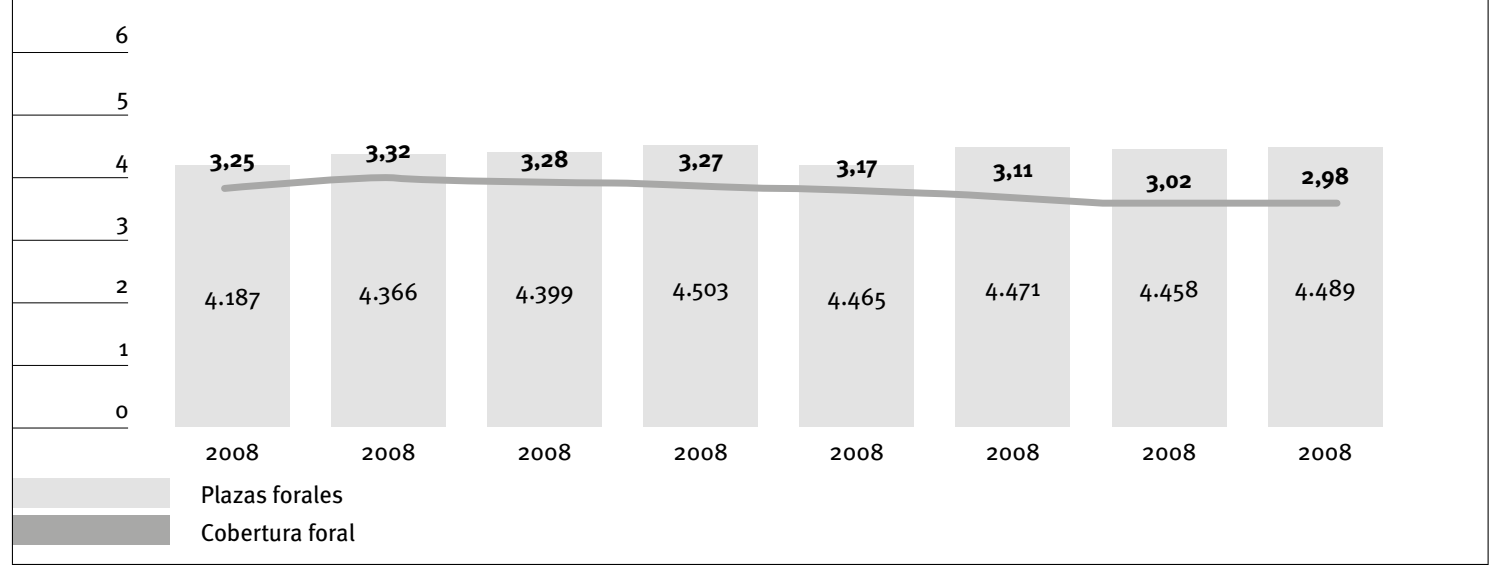

Fuente: Behagi (Departamento de Políticas Sociales, Diputación Foral de Gipuzkoa).

${ }^{4}$ Este porcentaje ha sido calculado considerando las 5.389 plazas autorizadas en residencias y las 653 plazas municipales en apartamentos tutelados y viviendas comunitarias existentes en Gipuzkoa.

${ }^{5}$ Existen plazas autorizadas de residencias en 64 centros; sin embargo, dos de ellos, que en total disponen de 105 plazas, no conciertan actualmente ninguna plaza con la Diputación.
${ }^{6}$ Pese a que los centros propios de la Diputación cuentan con un total de 966 plazas, sólo 837 son plazas forales. 
2.3. La demanda de servicios residenciales, el perfil de las personas usuarias y la calidad de la atención

Los datos relacionados con las listas de espera ofrecen información fiable sobre la demanda actual expresada no cubierta por la red pública de servicios sociales. En lo referente a los centros residenciales para personas mayores de competencia foral, si se analiza la evolución reciente de la lista de espera, se observa una progresiva reducción hasta 2013. Esta tendencia se ve interrumpida, sin embargo, en 2014 debido -en buena medida- al incremento del número de solicitudes de acceso. Los datos disponibles a 31 de diciembre de 2015 señalan que la lista de espera para acceder a un centro residencial para personas mayores era de 743 personas, y que el tiempo medio de espera entre la solicitud del servicio y el acceso a éste era de 139 días.

Otro aspecto relacionado con la demanda es el cambio registrado en las características y los perfiles de las personas atendidas en esos centros, según los agentes involucrados en la prestación de servicios. De acuerdo con lo señalado por la práctica totalidad de las personas consultadas, el cambio básico que se ha producido a lo largo de estos años se refiere a la emergencia de un perfil de personas usuarias de mayor edad, con un mayor grado de dependencia y con necesidades sociosanitarias -especialmente de carácter psiquiátrico o psicogeriátrico-más intensas. Este cambio en el perfil de las personas usuarias implica un cambio en la definición del propio servicio residencial, que tiene una carga sociosanitaria cada vez mayor - aun en el caso de los centros residenciales que no se consideran estrictamente sociosanitarios-, en detrimento de la atención psicosocial, socioeducativa o sociocultural que también corresponde prestar a este tipo de centros.

Destaca también en este sentido - a juicio, al menos, de algunas de las personas consultadasun cierto cambio en las expectativas y pautas de comportamiento de las personas usuarias, más acostumbradas ahora que en el pasado al ejercicio de sus derechos y a la manifestación de sus preferencias. Parece haber, en ese sentido, cierto consenso a la hora de señalar que las personas que actualmente acceden a los centros residenciales lo hacen con un mayor nivel de formación y que son más conscientes de sus derechos, más exigentes respecto al servicio recibido y, por decirlo de alguna manera, más capaces de verse a sí mismas como consumidoras de un servicio público - por el que pagan una tarifa o unos impuestos - y no como meras beneficiarias de una ayuda social. Todo ello pone de manifiesto la necesidad de avanzar en la línea de la individualización y la autodeterminación de las personas usuarias, no sólo porque se considere un enfoque técnica o filosóficamente adecuado, sino por la propia demanda de las personas usuarias.

En cuanto a las preferencias de las personas potencialmente demandantes $-y$ sus familias $-y$ la percepción sociocultural que existe en relación con los servicios residenciales, algunas de las personas consultadas ponen de manifiesto la persistencia de un cierto estigma o prejuicio asociado a los centros residenciales, que lleva a menudo a retrasar en la mayor medida posible el ingreso en un centro residencial, recurriendo a esa opción

Gráfico 5. Evolución de la lista y del tiempo medio de espera para acceder a plazas residenciales forales para personas mayores. Gipuzkoa, 2011-2015 y 2013-2015

Lista de espera
(número de personas)

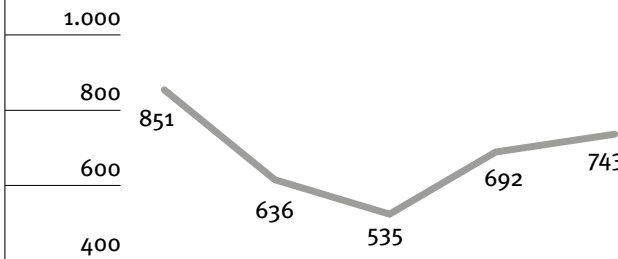

400

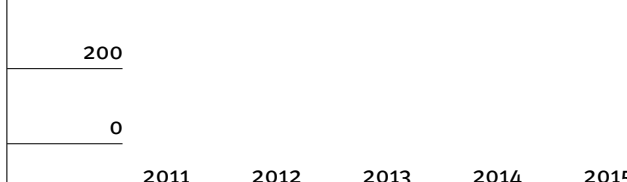

150

100

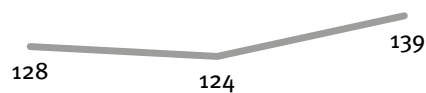

Tiempo de espera

(días)*



2013

2014

2015

* El tiempo medio de espera expresa el número medio de días naturales que transcurren entre la solicitud del servicio y el acceso a éste en el caso de las personas que han accedido a lo largo de cada año a ese recurso.

Fuente: Behagi (Departamento de Políticas Sociales, Diputación Foral de Gipuzkoa). 
sólo en los casos en los que el ingreso se considera inevitable o impostergable. De esta manera, las personas que acceden a estos recursos suelen ser mayoritariamente personas con necesidades asistenciales muy pesadas y una muy corta esperanza de vida.

Frente a esta situación, todas las personas consultadas insisten en que no debe modificarse el paradigma en el que se basan las políticas de atención a las personas mayores en Gipuzkoa, que parten de la idea de potenciar el envejecimiento en el domicilio, buscando de forma generalizada un acceso más temprano o precoz a los centros residenciales7. Sí se plantea, sin embargo, la necesidad de tener en cuenta este problema -el hecho de que algunas personas posponen en exceso el ingreso en una residencia, en detrimento de su calidad de vidamediante tres estrategias complementarias: reforzar los servicios preventivos, de atención primaria o de apoyo domiciliario, modificar el imaginario social que existe en relación con las residencias mediante un trabajo de información y sensibilización, y modificar los aspectos organizativos de los centros residenciales para incrementar su atractivo.

Respecto a la calidad de la atención, una buen parte de las personas consultadas valora de forma positiva la atención prestada en los centros residenciales, si bien reconoce también que pueden y deben aplicarse mejoras en lo que se refiere a la individualización de la atención, a los perfiles y dotaciones del personal de atención directa y a la adecuación de los espacios físicos de los centros residenciales. En cualquier caso, al analizar la calidad y la adecuación de la atención prestada en los centros residenciales, uno de los debates que surge es el relativo a la necesidad de introducir el paradigma de la atención centrada en la persona, y se plantea la discusión sobre en qué medida el conjunto de los centros han sido capaces de implementar una atención suficientemente individualizada. Si bien la idea de la individualización de la atención se acepta de forma generalizada, se plantean dos posturas relativamente contrapuestas: mientras que algunas personas consideran que se ha avanzado claramente en ese sentido, otras piensan que no se ha avanzado todavía suficientemente en este aspecto, y que la consolidación de una atención más integral, más individualizada, y más orientada a la autodeterminación y la capacidad de elección de la persona sigue siendo un reto pendiente del modelo residencial guipuzcoano.

\footnotetext{
${ }^{7}$ Aun sin abogar por un cambio drástico de modelo, algunas personas sí plantean en todo caso la necesidad de revisar la idea de que todas las personas están en cualquier caso mejor en su domicilio, y de reconocer que hay casos en los que la opción residencial es más aconsejable para todas las partes implicadas. Ello lleva también, de acuerdo con lo señalado por algunas de las personas que han participado en el debate, a reconocer el derecho a 'no cuidar' que asiste a las personas a las que se atribuye, en la práctica, la obligación de cuidar a sus familiares con dependencia ("No hay que denigrar el cuidado informal, pero tiene que ser elegido, tiene que haber alternativas").
}

En todo caso, dejando al margen ese debate, existe un amplio acuerdo al señalar el efecto positivo que tuvieron, en cuanto a la mejora de la calidad de la atención, los esfuerzos de ordenación y clarificación del modelo de atención a las personas mayores realizados a mediados de la pasada década, si bien algunas personas destacan también la necesidad de actualizar algunos de los elementos del modelo definido hace ya casi diez años ${ }^{8}$.

En ese sentido, uno de los elementos básicos del Catálogo de servicios residenciales para personas mayores aprobado en 2007, aunque no el único, radica en la exigencia de unos perfiles profesionales determinados y de unas ratios de atención directa superiores a los establecidos por la normativa autonómica entonces y todavía en vigor (Decreto 41/1998). A la hora de valorar la adecuación de las ratios establecidas en ese documento, las opiniones de las personas consultadas son claramente divergentes, y sólo en algunos aspectos la necesidad de reforzar determinadas figuras, por ejemplo puede hablarse de un cierto acuerdo. Por lo demás, las opiniones se dividen entre quienes consideran que las ratios establecidas en el Catálogo garantizan un servicio de calidad suficiente y son muy superiores a las que se exigen en otros territorios o comunidades autónomas, y quienes consideran que deberían incrementarse 0 , al menos, rediseñarse en función de un nuevo modelo de atención, de carácter más individualizado:

- Las personas partidarias de revisar y, en su caso, incrementar las ratios exigidas opinan que la normativa vigente no responde a los requerimientos del actual mix de usuarios de las residencias y que no se incorporan además todas las figuras profesionales necesarias para prestar una atención individualizada e integral. Se señala también que el Catálogo parte de una concepción muy medicalizada de la atención residencial. Frente a estas insuficiencias, algunas personas proponen una flexibilización de los roles y perfiles profesionales, así como el incremento de las ratios de las auxiliares de geriatría, para poder reforzar la atención personal desde una perspectiva más individualizada y más orientada a la estimulación de las personas residentes 9 .

\footnotetext{
${ }^{8}$ En 2004 se puso en marcha una ponencia en Juntas Generales para la definición de un modelo integral de atención a las personas mayores en el territorio. Fruto de aquel proceso se elaboraron diversos documentos, como el Documento estratégico sobre la atención a las personas mayores dependientes de Gipuzkoa, el Modelo de atención a las personas mayores en Gipuzkoa y, algo más tarde, el Catálogo de servicios residenciales para personas mayores, establecido por parte de la Diputación Foral de Gipuzkoa en 2007.

${ }_{9}$ Cabe señalar, a este respecto, que las experiencias piloto realizadas en nuestro entorno para la introducción de un modelo centrado en la persona en el ámbito residencial implicaban, entre otras mejoras y adaptaciones conexas, un incremento de la ratio de auxiliar de geriatría del $17 \%$ en el caso de las plazas para grandes dependientes y del $22 \%$ en el caso de las plazas psicogeriátricas, en relación con el Catálogo actual. Por otra parte, algunas investigaciones realizadas para adecuar las ratios de atención a la carga asistencial que requieren las personas actualmente residencializadas apuntan a la necesidad de incrementar en torno a un $10 \%$ la ratio de gerocultores/as.
} 
- Para otras personas, sin embargo, plantear un incremento de las ratios de atención - que ya están por encima de las exigidas en otros ámbitos territoriales y que se consideran, en ciertos aspectos, demasiado altas- carece de sentido y no supondría un incremento en la mejora de la atención, aunque sí un coste añadido para las entidades gestoras de los centros.

Finalmente, y desde una perspectiva algo distinta, otras personas rechazan focalizar el debate sobre la calidad de la atención en el asunto de las ratios de atención directa y se centran en la necesidad de revisar el modelo de atención en su integridad, para derivar de ahí, en todo caso, una modificación de las ratios (no necesariamente al alza). Desde este punto de vista, un eventual incremento de las ratios de atención debería venir acompañado de -o enmarcarse en- el desarrollo de un modelo diferente de atención.

\section{Personal ocupado, situación salarial y condiciones laborales}

Examinados el número de centros y de plazas residenciales, así como las características de las personas atendidas, la satisfacción de la demanda y las cuestiones relacionadas con la calidad de la atención, este apartado analiza los datos disponibles en relación con el personal que presta sus servicios en los centros residenciales guipuzcoanos. Además de las ratios de atención que se derivan de las dotaciones de personal registradas, también ofrece información relativa a la remuneración y las condiciones laborales de las personas ocupadas en servicios de atención residencial.

\subsection{Ocupación en el sector y ratio de personal}

De acuerdo con las cifras que proporciona la Estadística de Servicios Sociales y Acción Social en 2013, el personal medio anual ocupado en los servicios residenciales para personas mayores en Gipuzkoa alcanzaba la cifra de 4.032 trabajadores y trabajadoras, de los cuales 2.488 formaban parte del personal propio de los centros y 1.544 (el $38 \%$ ) eran trabajadores y trabajadoras subcontratados de atención directa ${ }^{10}$. El importante volumen de personas ocupadas en este sector queda patente cuando se comprueba que éstas representan algo más de la mitad (el $51 \%$ ) de todas las personas ocupadas en el núcleo de los servicios sociales en Gipuzkoa $^{11}$ (7.908 trabajadores/as) y el 1,94\% de la población ocupada en el sector servicios ${ }^{12}$.

Tal y como cabría esperar - debido no sólo a su mayor dotación de plazas, sino también a la mayor intensidad de la atención prestada-, de todas las

Gráfico 6. Evolución del personal ocupado en diversos sectores. Gipuzkoa, 2002-2013

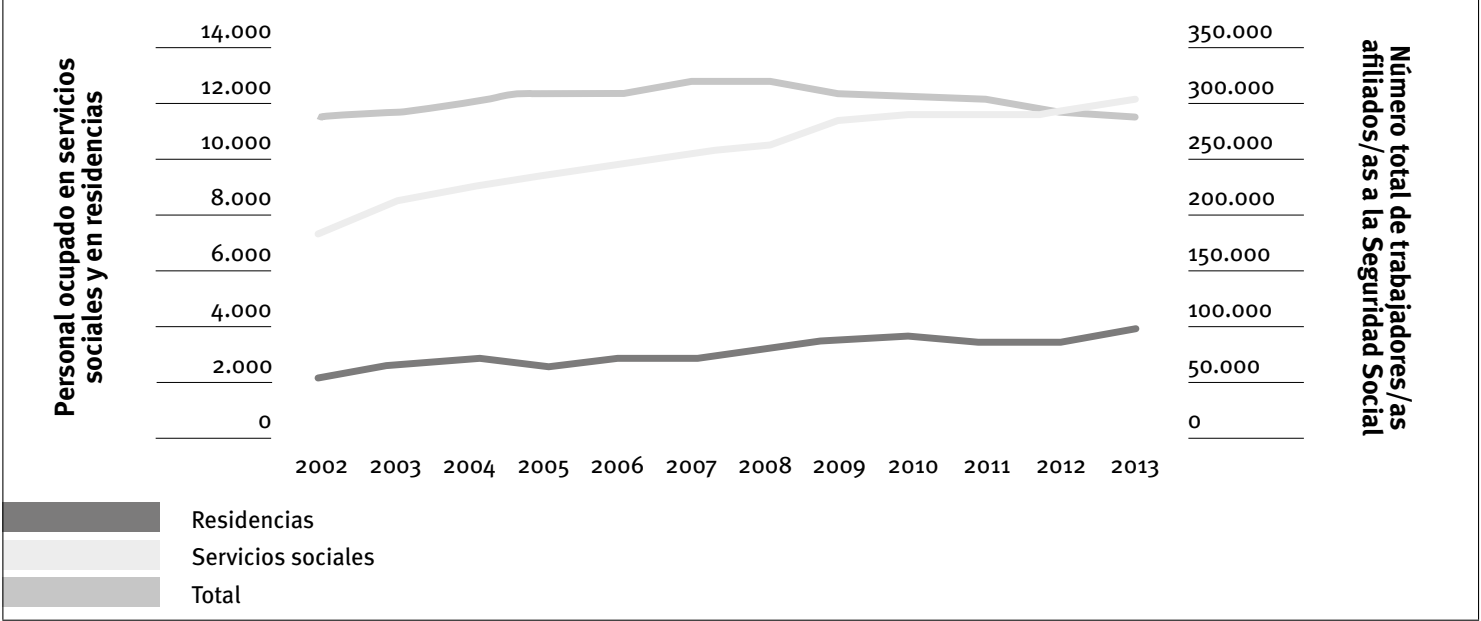

Fuentes: Estadística de Servicios Sociales y Acción Social (Órgano Estadístico Específico del Departamento de Empleo y Políticas Sociales del Gobierno Vasco) y afiliación de trabajadores a la Seguridad Social (Ministerio de Empleo y Seguridad Social). Los datos sobre residencias de 15 y más plazas, así como los del conjunto de los servicios sociales hacen referencia al personal medio anual ocupado en estos sectores, se incluyen tanto el personal propio como el subcontratado de atención directa. Los datos de afiliación, por su parte, corresponden al 31 de diciembre de cada año.

${ }^{10}$ Se trata de personas puestas a disposición de los centros de servicios sociales por empresas subcontratadas que prestan servicios de atención directa a las personas usuarias.

${ }^{11}$ Por núcleo de los servicios sociales se entienden aquellos servicios y prestaciones más directamente vinculados a los recogidos en el Decreto $185 / 2915$ de Cartera de Servicios Sociales.

${ }_{12}$ Los datos provienen de la Encuesta Población en relación con la actividad (PRA) de Eustat correspondiente al cuarto trimestre de 2013, que cifra la población ocupada en el sector servicios en 207.500 personas. 
personas ocupadas en los servicios residenciales para personas mayores (4.032), la gran mayoría (el $94 \%$ ) corresponde a los centros residenciales, correspondiendo el $6 \%$ restante a las viviendas y los apartamentos. Desde el punto de vista evolutivo, el Gráfico 6 pone de manifiesto la capacidad de generación de empleo que ha demostrado a lo largo de los últimos años el sector de los servicios sociales y, dentro de él, los centros residenciales para las personas mayores. Así, si entre 2008 y 2013 el número total de ocupados descendió en Gipuzkoa en un $8 \%$, en el ámbito de los servicios sociales creció en un $15 \%$ y en lo que se refiere a los centros residenciales en un $31 \%$, pasando de poco más de 2.800 personas ocupadas a cerca de 3.800 .

Cabe señalar, más brevemente, dos aspectos adicionales sobre el personal propio ocupado en los centros residenciales guipuzcoanos ${ }^{13}$. Por una parte, la elevadísima tasa de feminización del personal, que representa el $89 \%$ del total (aunque sólo el $76 \%$ del personal de dirección y Administración), y, por otra, el elevado peso del personal sanitario, que representa el $62 \%$ del personal propio ${ }^{14}$, mientras que el personal de servicio representa el $23 \%$ y el técnico y educativo apenas algo menos del $7 \%$.

\subsection{La remuneración del personal ocupado}

Según la Estadística de Servicios Sociales y Acción Social, en Gipuzkoa, la retribución media anual ${ }^{15}$ correspondiente al personal propio de los servicios residenciales para personas mayores alcanzó en 2014 los 33.729 euros anuales. Se trata de una cuantía un $4,8 \%$ inferior a la registrada en el conjunto de la economía vasca, que ese mismo año refería, según la Encuesta Anual de Coste Laboral del INE, una retribución media anual ${ }^{16}$ de 35.426 euros. Si se

${ }^{13}$ Estos datos recogen únicamente la cualificación del personal propio de los servicios residenciales para mayores. No incluyen, sin embargo, la del personal subcontratado de atención directa, que representa algo más de la tercera parte de todo el personal ocupado en este sector, ya que la Estadística de Servicios Sociales y Acción Social no consigna esta información.

${ }^{14}$ Debe señalarse, en cualquier caso, que el conjunto de los y las auxiliares de geriatría se imputan a este grupo, si bien no puede considerarse que su función sea estrictamente sanitaria.

${ }^{15}$ En este concepto se considera la remuneración del personal asalariado según la clasificación SEC1995 - C4.02. Se incluye, por tanto, toda remuneración abonada por el personal empleador como contrapartida al trabajo realizado durante el periodo contable. En este caso, la remuneración salarial comprende tanto los sueldos y salarios (D.11), como las cotizaciones sociales a cargo del personal empleador (D.12). Asimismo, para el cálculo de la retribución media se han considerado las personas trabajadoras con dedicación plena, y de forma específica, el personal propio a 15 de diciembre en equivalencia a jornada laboral de 35 horas/semanales. En todo caso, estos datos deben ser considerados a efectos meramente ilustrativos. La principal razón es que el cálculo de la retribución media se realiza a partir exclusivamente del personal propio de los centros, es decir, a partir del número de personas que es contratada directamente por los centros. No se tienen en cuenta, por tanto, a aquellas personas puestas a disposición de los servicios residenciales por empresas subcontratadas que prestan servicios de atención directa a las personas usuarias y que suponen en 2013 , por poner un ejemplo, el $66 \%$ de las personas ocupadas en los servicios residenciales de titularidad pública y un $16 \%$ de los de titularidad privada.

${ }^{16}$ Este dato ha sido extraído de la Encuesta Anual de Coste La- compara la retribución media del personal asalariado en los servicios residenciales para personas mayores de Gipuzkoa con la de otros sectores económicos, los resultados sugieren que se sitúa al mismo nivel que el sector servicios en su conjunto, pero que resulta casi un $20 \%$ menor que la retribución media correspondiente al sector de la industria en el conjunto de la comunidad autónoma del País Vasco (CAPV).

\section{Obviamente, los datos considerados deben ser} interpretados con las debidas cautelas. En primer lugar, porque se trata de cantidades medias y, por tanto, pueden esconder una amplia diversidad de situaciones, pero también, porque los datos que se comparan proceden de metodologías diferentes ${ }^{17}$. Teniendo esto en cuenta, se observa que la retribución media en los servicios residenciales de Gipuzkoa ha experimentado desde 2008 hasta 2014 un incremento superior (del $10 \%$ ) al observado en el conjunto de la economía (que es del $6 \%$ ). De hecho, si a la hora de analizar estos datos se detrae de ellos el incremento atribuido a las subidas del IPC anuales (Gráfico 7), lo que se observa es una disminución real de los salarios tanto en el caso de la economía vasca en su conjunto $(-3,2 \%)$, como en el del sector servicios $(-3,1 \%)$, pero no así en el sector residencial guipuzcoano, que (pese al decremento de 2009) logra mantener su retribución anual en niveles similares a los de 2008. De hecho, en ese periodo la remuneración en el sector pasa del $91 \%$ de la remuneración media en el conjunto de la economía al $95 \%$.

Los datos procedentes de la Estadística de Servicios Sociales y Acción Social permiten también comparar los niveles retributivos del personal asalariado del sector de las residencias para mayores en Gipuzkoa de cada una de las dos redes, pública y privada, en las que pueden dividirse estos centros según su titularidad. Uno de los rasgos más llamativos que se observan en torno a esta cuestión, no sólo en Gipuzkoa, sino también -y de forma más acusadaen Álava y Bizkaia, es la importante brecha salarial existente entre el personal propio de los centros públicos y el de los centros de titularidad privada (Gráfico 8).

boral del INE. Dado que la operación estadística en cuestión diferencia con detalle cada uno de los parámetros que componen el coste laboral, han sido extraídos los mismos componentes que los considerados en la Estadística de Servicios Sociales y Acción Social del Gobierno Vasco. De este modo, al hablar de retribución media se han incluido todas las remuneraciones abonadas a los trabajadores por la prestación profesional de sus servicios laborales por cuenta ajena; incluye, por tanto, el salario base, los complementos salariales, los pagos por horas extraordinarias, los pagos extraordinarios y los pagos atrasados. Asimismo, también se han incluido todas las cotizaciones sociales a cargo del personal empleador.

17 En el caso de la Estadística de Servicios Sociales y Acción Social, los datos obtenidos son censales y la información relativa a las retribuciones de las personas trabajadoras se recoge de forma agregada en el marco de los datos económicos de gasto corriente correspondiente a los centros de servicios sociales. Por otra parte, la Encuesta Anual de Coste Laboral es muestral (si bien el error de muestreo para la CAPV se sitúa por debajo de 1,4\%), y en este caso, sí se trata de una operación específica, pues su objetivo fundamental es conocer los niveles anuales de coste laboral medio por persona trabajadora, detallando sus principales componentes. 


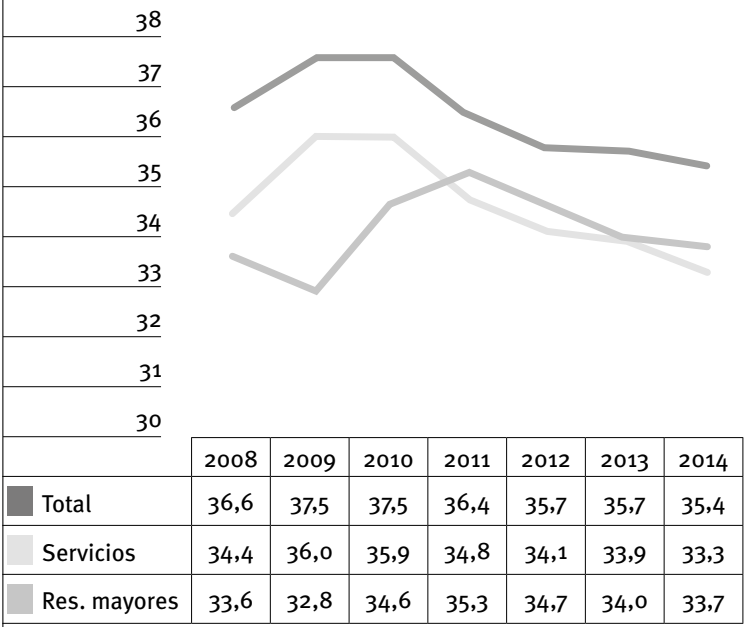

Incremento 2008-2014 (\%)

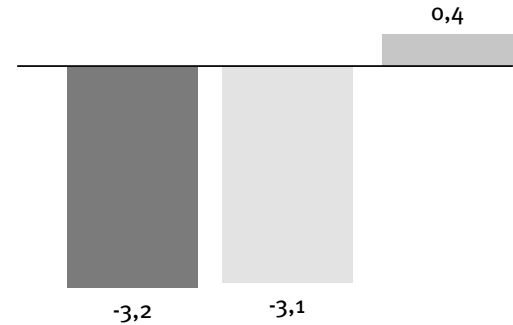

Total

Servicios

Res. mayores

Fuentes: Estadística de Servicios Sociales y Acción Social (Órgano Estadístico Específico del Departamento de Empleo y Políticas Sociales del Gobierno Vasco), Encuesta Anual de Coste Laboral (INE) e Índice de Precios de Consumo (INE).

Gráfico 8. Retribución media anual del personal ocupado en los servicios residenciales para mayores, por titularidad de los centros. CAPV, 2014 (euros)

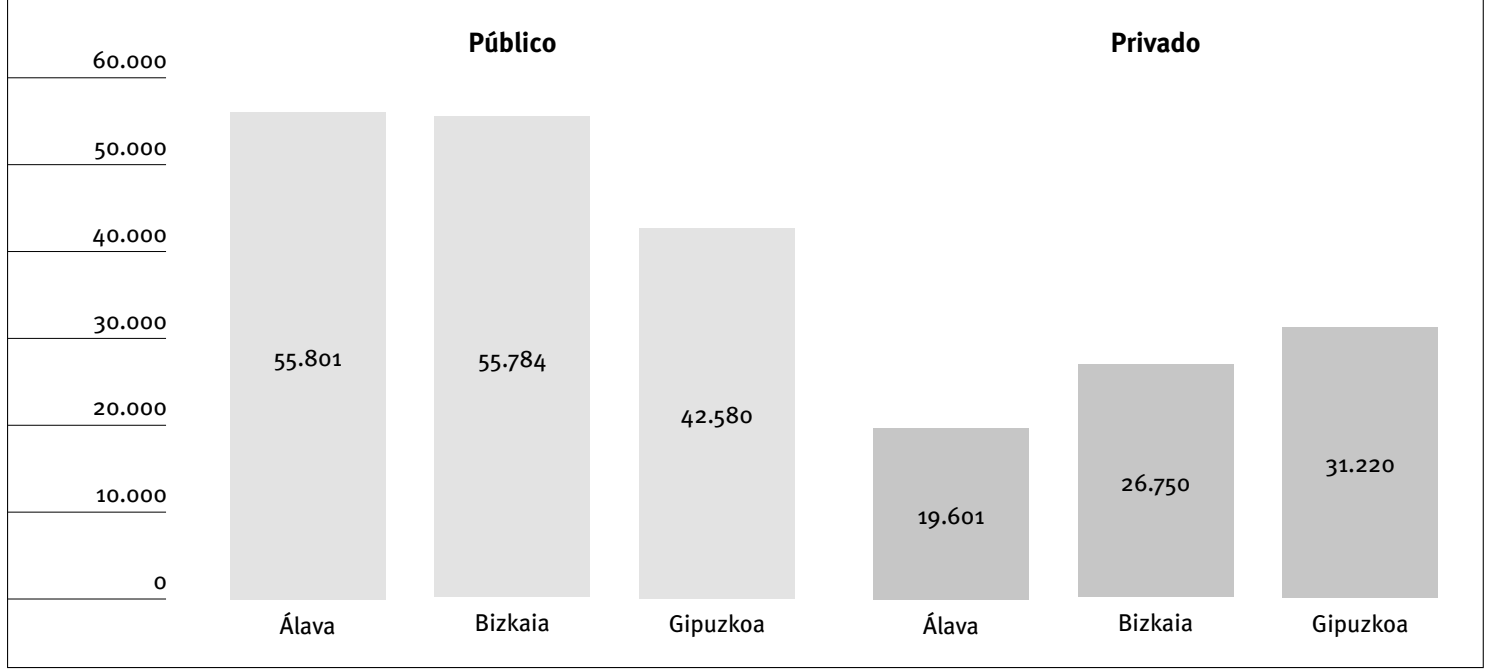

Fuente: Estadística de Servicios Sociales y Acción Social 2014 (avance) [Órgano Estadístico Específico del Departamento de Empleo y Políticas Sociales del Gobierno Vasco].

Por otra parte, y desde un punto de vista evolutivo, los datos disponibles para Gipuzkoa muestran que a lo largo de la última década la retribución media en ambas redes ha tendido a converger, de tal manera que si en 2002 la retribución media en centros de titularidad privada apenas alcanzaba el $48 \%$ de la correspondiente a los centros de titularidad privada, en 2014 la proporción es del $73 \%$. La razón de esta convergencia radica en que la retribución media en el sector privado ha aumentado más que la registrada en los centros de titularidad pública.

Tal y como puede observarse en el Gráfico 9, donde los resultados se presentan en términos de euros constantes, para el periodo comprendido entre
2002 y 2014, el incremento interanual medio de la retribución correspondiente a los centros de titularidad privada se ha situado en un $4,6 \%$, mientras que el de los centros de titularidad pública apenas habría sido de un $1 \%$ (debido sin duda a las medidas de contención del déficit público adoptadas por las Administraciones públicas a lo largo de los últimos años). Si estas cifras se comparan con las obtenidas para los otros dos territorios, se observa que Gipuzkoa es el territorio en el que la retribución media del personal propio de los centros residenciales ha crecido en mayor medida. Esta consideración puede extenderse tanto a los centros de titularidad privada como a los de titularidad pública. 




Fuente: Estadística de Servicios Sociales y Acción Social (Órgano Estadístico Específico del Departamento de Empleo y Políticas Sociales del Gobierno Vasco) e Índice de Precios de Consumo (INE).

\subsection{Condiciones laborales}

En concordancia con la información cuantitativa disponible, la mayor parte de las personas consultadas ponen de manifiesto la mejora que se ha producido en los últimos años en lo que se refiere a las condiciones laborales del personal y, de hecho, consideran que este elemento constituye una de las principales fortalezas del sector. No todas las personas consultadas tienen, sin embargo, una visión tan optimista y se señala, en este sentido, la persistencia de diferencias en las condiciones laborales del personal, dependiendo tanto del tipo de contratación - personal propio o subcontratadoy de la titularidad del centro - público o privado-, como del modelo de gestión - directa o indirecta-. A juicio de estas personas, si bien es cierto que las diferencias han tendido a reducirse en los últimos años, siguen siendo muy notables, tanto desde la perspectiva salarial como desde otros puntos de vista (turnos, horarios). Se señala en ese sentido que la falta de un convenio sectorial y el hecho de que se hayan multiplicado los convenios de empresa provocan distorsiones que se acentúan en función de la forma de contratación del personal (contratación directa, empresas de trabajo temporal, subcontratas).

Por otra parte, algunas de las personas consultadas indican -en relación básicamente con las residencias municipales-que se han dado por válidas condiciones laborales muy beneficiosas para los trabajadores, que derivan en déficits muy elevados en los Ayuntamientos, razón por la cual éstos han querido renunciar a la gestión de esos centros. En este sentido, no se puede olvidar que la cuestión de las condiciones laborales (y, particularmente, las salariales) tiene una relación directa con la viabilidad económica del servicio, lo cual, aunque sea indirectamente, cuestiona el modelo de concertación establecido. Algunas de las personas consultadas critican así la injerencia de la Administración en la determinación de las condiciones laborales del personal ocupado, señalando que su implicación en este aspecto ha excedido en algunos momentos la que corresponde a la parte contratante de un servicio.

En este sentido, algunas de las personas consultadas se muestran especialmente críticas con la política que durante la pasada legislatura se siguió en relación con la mejora de las condiciones laborales del personal de las residencias privadas, señalando las negativas consecuencias del contexto de conflictividad laboral vivido durante los últimos años y su desacuerdo con las reivindicaciones de las centrales sindicales. En todo caso, dada la procedencia de las personas participantes en el debate, no todas están de acuerdo con esta visión y existen posturas divergentes sobre el papel que debe jugar la Administración $-y$, concretamente, la Administración foral- en la definición de las condiciones laborales: mientras que algunas de las personas consultadas consideran que debe limitarse a garantizar un marco de actuación estable, reduciendo al mínimo toda injerencia o intervención en el sector, otras consideran, por el contrario, que no pueden desvincularse de las condiciones en las que se presta el servicio que conciertan.

En todo caso, para algunas de las personas consultadas, una de las consecuencias de lo que consideran una excesiva injerencia de la Administración en la determinación de las condiciones laborales del sector ha sido el incremento del absentismo que se ha producido en los últimos años, y que se achaca a la obligación impuesta a las empresas gestoras de centros 
concertados de cubrir la totalidad de las bases de cotización en caso de incapacidad laboral, de forma que si ésta se produce se percibe el salario íntegro. Para estas personas, no habiendo diferencia en cuanto a la remuneración económica en caso de baja, el absentismo se ha disparado en los últimos meses, con el efecto que ello tiene tanto para la calidad de la atención como para la viabilidad económica de los centros. Se señala además que determinadas condiciones establecidas en los convenios laborales impiden la necesaria flexibilidad en la prestación del servicio y, en la práctica, dificultan la adopción de un enfoque centrado en la persona.

A partir de estas consideraciones, la mayor parte de las personas entrevistadas se muestran favorables a la firma de un convenio sectorial, de ámbito provincial, que permita ir unificando las condiciones laborales de todo el personal, independientemente de la titularidad o gestión del centro, y de la forma de contratación, y que permita además adaptar las condiciones laborales a un servicio con unas características (como la atención durante las 24 horas) muy determinado. Algunas de las personas que han participado en los debates señalan también que, en ausencia de un convenio de este tipo, la Diputación debería establecer una serie de mínimos relacionados con la calidad del empleo en los centros concertados, bien mediante cláusulas sociales, bien mediante otras fórmulas. También se señala al respecto que, siendo difícil para las empresas y para la Administración, seguir avanzando en la mejora de las condiciones salariales, las mejoras laborales que a partir de ahora se puedan implementar deberían estar relacionadas con la flexibilidad, la polivalencia y la consideración de las necesidades del personal en lo que se refiere a la conciliación laboral.

Junto con las cuestiones señaladas, algunas de las personas consultadas ponen también de manifiesto la necesidad de adoptar medidas más ambiciosas para dar una respuesta a los riesgos laborales -especialmente, los de carácter psicosocial- a los que se enfrentan los y las profesionales de atención directa, cuya edad media es cada vez mayor. Ello implica un incremento del riesgo de lesiones y enfermedades, que serían la causa del incremento de las tasas de absentismo y no, según estas personas, el derecho a percibir el salario íntegro en caso de baja. Algunas personas añaden a propósito de los riesgos laborales que -al igual que ocurre en otros ámbitos asistenciales en los que hay una relación directa con las personas usuarias - se viene produciendo en los últimos años un incremento en las situaciones de riesgo (muy a menudo derivadas de la mayor prevalencia de los trastornos mentales y de conducta), ante los cuales la plantilla se siente desprotegida y poco respaldada. Algunas de las personas consultadas reclaman, en este sentido, una mayor atención a los riesgos psicosociales a los que se enfrenta el personal de atención directa de las residencias.

No puede decirse, finalmente, que el asunto de la formación y la cualificación suponga una preocupación de primer orden para las personas consultadas, puesto que apenas ha sido mencionada en los cuestionarios y en los grupos de discusión. Se señala, en este sentido, que las exigencias de acreditación han tenido como consecuencia una mejora en la cualificación de los profesionales y se reclama, en cualquier caso, un mayor apoyo por parte de las Administraciones para realizar actividades formativas.

\section{Análisis económico}

Tras examinar la información relativa a la atención $y$ al personal ocupado en los centros residenciales de Gipuzkoa, se analizan a continuación diversos parámetros económicos de las residencias para personas mayores. Para ello, se recurre a los datos disponibles sobre el gasto realizado para el sostenimiento de los centros, el coste medio de las plazas residenciales y la estructura de financiación de dicho gasto, con particular atención a la participación económica de las personas usuarias en la financiación de los centros residenciales.

\subsection{El gasto en servicios residenciales}

En 2013, según se desprende de los últimos datos disponibles de la Estadística de Servicios Sociales y Acción Social, el gasto corriente de la atención residencial a las personas mayores en nuestro territorio ascendió a 170,5 millones de euros ${ }^{18}$. De todo el gasto corriente realizado, casi 164,8 millones de euros, el $97 \%$ del gasto total, se dirigió a las residencias para personas mayores, y en torno a 5,7 millones, a sufragar otras modalidades residenciales que implican un cuidado menos intensivo (viviendas y apartamentos). Asimismo, debe señalarse también que, de todo el gasto realizado, el $58 \%$ fue gasto público, esto es, financiado por las diferentes Administraciones públicas con competencias sobre el sector y que un $42 \%$ fue gasto privado.

Desde un punto de vista comparado, tal y como se observa en el Gráfico 10, el gasto corriente medio de Gipuzkoa se sitúa entre el alavés y vizcaíno. En este sentido, puede apuntarse que en 2013 el gasto corriente por persona mayor en atención residencial ascendió en Gipuzkoa a 1.185,2 euros. Este gasto fue un $21 \%$ menor que el realizado en Álava $(1.497,7)$ pero un $9 \%$ superior al gasto vizcaíno en servicios residenciales para personas mayores $(1.088,5)^{19}$.

${ }_{18}$ Los datos que avanza la Estadística de Servicios Sociales y Acción Social señalan que, para 2014, el gasto corriente total en servicios residenciales para personas mayores en Gipuzkoa ascendió a 175,2 millones de euros, lo que supone un incremento del $2,8 \%$ respecto al realizado en 2013. Dado que todavía no es posible acceder a información desagregada sobre el gasto de 2014, el análisis de este epígrafe se centrará fundamentalmente en los datos de 2013.

${ }^{19} \mathrm{~A}$ pesar de que entre 2013 y 2014 el incremento total del gasto corriente es de un 2,8\% en Gipuzkoa y dado el aumento que registra cada año la cohorte de edad de 65 y más años, el gasto medio por persona mayor ( $1.188 €$ ) en 2014 es muy similar al registrado en 2013 $(1.185 €)$. 
Fuente: Estadística de Servicios Sociales y Acción Social (Órgano Estadístico Específico del Departamento de Empleo y Políticas Sociales del Gobierno Vasco).

Asimismo, los datos de evolución muestran que, al margen de la financiación de estos centros, el gasto corriente realizado en Gipuzkoa para sufragarlos ha crecido de manera importante. Según las cifras que proporciona la Estadística de Servicios Sociales y Acción Social, el gasto corriente en centros residenciales de 15 y más plazas para personas mayores habría pasado, en los últimos doce años, de 63,9 a 164,8 millones de euros. En otras palabras, el gasto corriente se habría multiplicado por 2,6, lo que habría supuesto un crecimiento del $158 \%$ o, expresado en euros constantes, un incremento del $96 \%$.

El ritmo de crecimiento de Gipuzkoa ha sido similar al correspondiente a Bizkaia: entre 2002 y 2013 , el crecimiento interanual medio guipuzcoano ha sido del $9 \%$ y el vizcaíno del 9,1\%. Mucho menor ha sido el ritmo de crecimiento del gasto residencial en Álava, situado en este periodo en torno a un 5,7\% interanual. Una de las consecuencias de la diferente intensidad interterritorial del crecimiento del gasto en residencias para personas mayores ha sido la tendencia hacia la reducción de las diferencias en el gasto medio por habitante. Debido a que Álava ha partido históricamente de un gasto medio por habitante comparativamente superior al de Bizkaia y Gipuzkoa, la menor aceleración de su gasto ha propiciado que las diferencias interterritoriales en 2013 sean menores que las observadas al inicio del periodo. Mientras que en 2002 el gasto medio por persona mayor de Álava era un $80 \%$ superior al de Gipuzkoa y un $110 \%$ más elevado que el de Bizkaia, en 2013 estas proporciones se reducen hasta el $20 \%$ y $33 \%$, respectivamente.

Entre las razones de la tendencia a la confluencia del gasto medio por persona mayor en centros residenciales, se encuentra la evolución del número de plazas: entre 2002 y 2013 , las plazas en servicios residenciales en Álava se han incrementado sólo en un $26 \%$, frente a crecimientos del $80 \%$ y $38 \%$ de Bizkaia y Gipuzkoa, respectivamente. Por otra parte, también ha podido tener un efecto importante la ya señalada evolución al alza en la retribución media del personal propio de estos centros, lo que se traduce, como se explica en el siguiente apartado, en un incremento superior del coste/plaza.

En definitiva, tanto en Bizkaia como en Gipuzkoa el gasto en residencias (descontando el IPC) se ha duplicado en diez años. Las razones que subyacen a esos incrementos son, sin embargo, distintas: mientras que en Bizkaia, el crecimiento del gasto se debe sobre todo a las creación de nuevas plazas, en Gipuzkoa la mayor parte del incremento se deriva del alza en el coste/plaza, que se relaciona, a su vez, en gran medida, con el incremento en los costes de personal. 

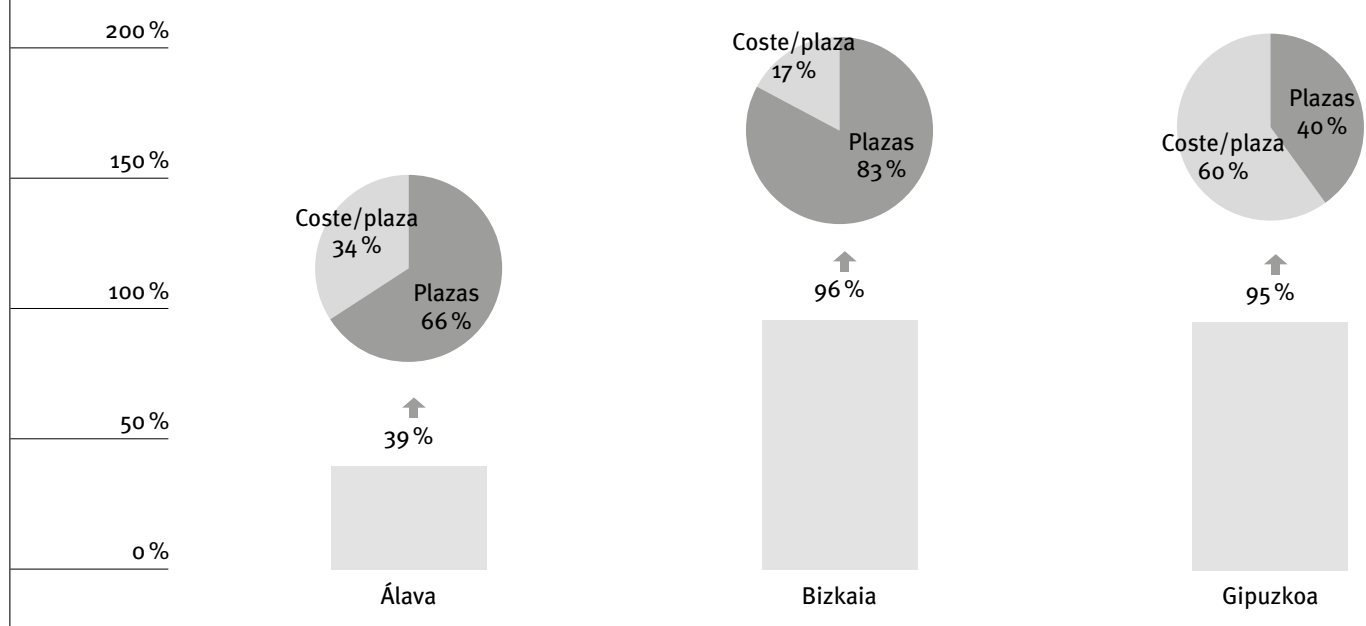

Fuente: Estadística de Servicios Sociales y Acción Social (Órgano Estadístico Específico del Departamento de Empleo y Políticas Sociales del Gobierno Vasco).

\subsection{Coste/plaza}

A la hora de analizar la evolución del coste/plaza, en primer lugar, debe tenerse en cuenta que el indicador económico gasto corriente/plaza se refiere al conjunto de los servicios residenciales para personas mayores, entre los que se incluyen tanto las residencias como los apartamentos tutelados y las viviendas comunitarias. Así, los datos correspondientes a 2013 ponen de manifiesto que el gasto corriente por plaza se situaba en 79,2 euros por día ${ }^{20}$.

Desde la perspectiva evolutiva, se observa que, desde 2002 y en euros constantes, el coste/plaza por día de los servicios residenciales ${ }^{21}$ para personas mayores, el gasto corriente por plaza ha crecido en un $40 \%$, pasando de 57,3 euros diarios a los señalados 80,7. La mayor parte del incremento, en cualquier caso, se registra entre 2002 y 2009 , estancándose el crecimiento del coste/plaza desde 2008 en torno a los 77 euros diarios. Desde 2008, en términos de euros constantes, el crecimiento interanual medio del coste/plaza ha sido del 1,1\%. Cabe pensar que este estancamiento del coste/ plaza se debe, básicamente, al estancamiento en la retribución del personal de los centros públicos.

Si se comparan los datos de Gipuzkoa con los del resto de territorios de la CAPV, se observa claramente (Gráfico 11) que, una vez descontado el efecto del IPC,

${ }^{20}$ Los datos más actuales de la Estadística de Servicios Sociales señalan que en 2014 el gasto corriente por plaza total fue algo superior, de 80,71 euros/día (29.459 euros/año). Sin embargo, aún no se ofrecen para este año datos desglosados por población destinataria.

${ }^{21}$ Dado que para el año 2014 no se dispone de datos desagregados en función de la población destinataria de los centros residenciales, los datos de evolución que se ofrecen a continuación hacen referencia al gasto corriente/plaza del conjunto de servicios residenciales para personas mayores. el coste/plaza de los centros guipuzcoanos es el que más ha crecido de los tres territorios.

Si se toma como referencia el periodo 2002 a 2014 y se analiza la evolución en euros constantes, el gasto corriente/plaza en Gipuzkoa habría pasado de 57,3 euros/día a 80,7 lo que habría supuesto un incremento del $40,9 \%$ o, lo que es lo mismo, un crecimiento interanual constante del 2,9\%. Frente a esta evolución, tanto Bizkaia como, sobre todo, Álava habrían registrado incrementos notablemente menores, de en torno al $15,7 \%$ y $10 \%$, respectivamente para todo el periodo. Esta convergencia interterritorial se debe, por una parte, al mayor crecimiento experimentado en Gipuzkoa en cuanto al número de plazas y, por otra, al mayor incremento del coste/plaza y de la retribución del personal.

\subsection{Aportación económica de las personas usuarias}

En este apartado, se analiza la información disponible en relación con la participación económica de las personas usuarias. Las fuentes estadísticas disponibles indican que el copago existente actualmente en los servicios residenciales para personas mayores en Gipuzkoa se sitúa, de media, en un $42 \%$ para el año 2014. Esto significa que a través de los ingresos y cuotas que abonan las personas usuarias, éstas estarían haciéndose cargo de en torno a un $42 \%$ del gasto corriente que implica la ocupación de una plaza residencial.

Como es obvio, este dato requiere ser matizado. En primer lugar, porque se trata de una media y, como tal, está sujeta a cierta simplificación. Asimismo, ha de tenerse en cuenta que los datos disponibles no se refieren exclusivamente al copago de las plazas de responsabilidad foral, ni tampoco a las de 


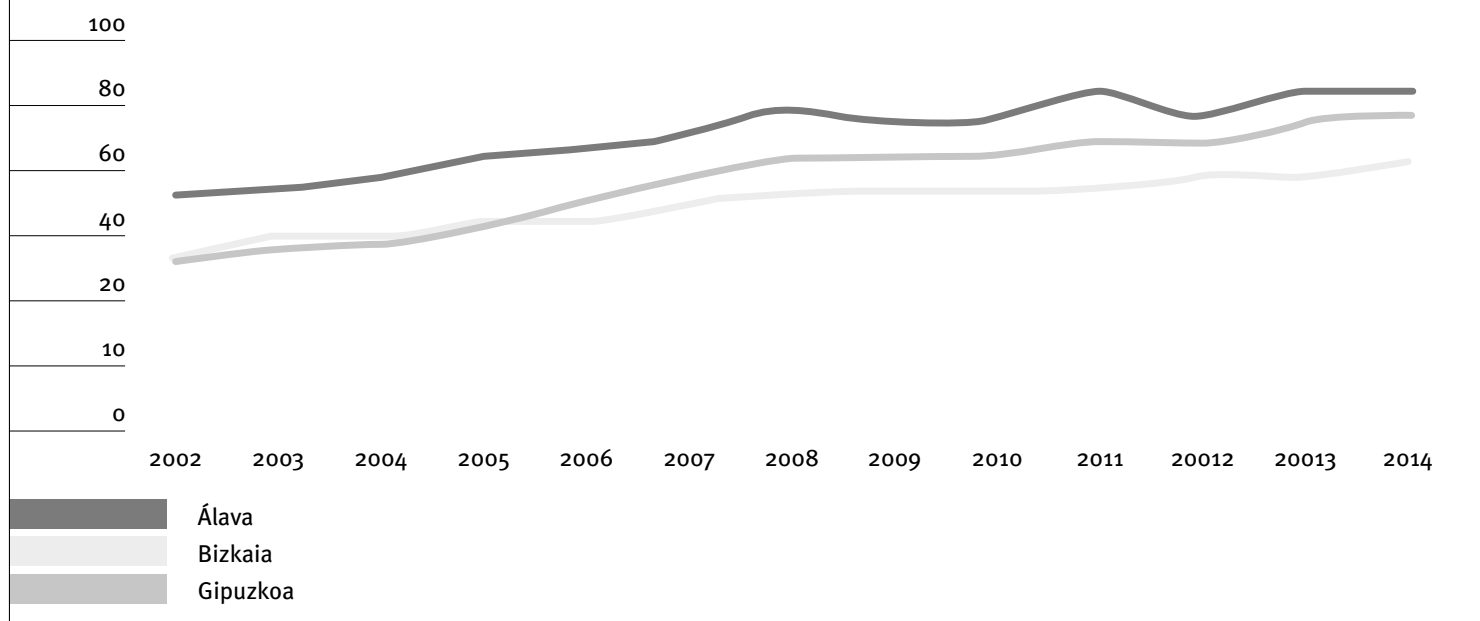

Fuente: Estadística de Servicios Sociales y Acción Social (Órgano Estadístico Específico del Departamento de Empleo y Políticas Sociales del Gobierno Vasco).

Gráfico 13. Incremento porcentual del gasto corriente/plaza de los servicios residenciales para personas mayores, por territorio histórico. CAPV, 2002-2014 (euros constantes)

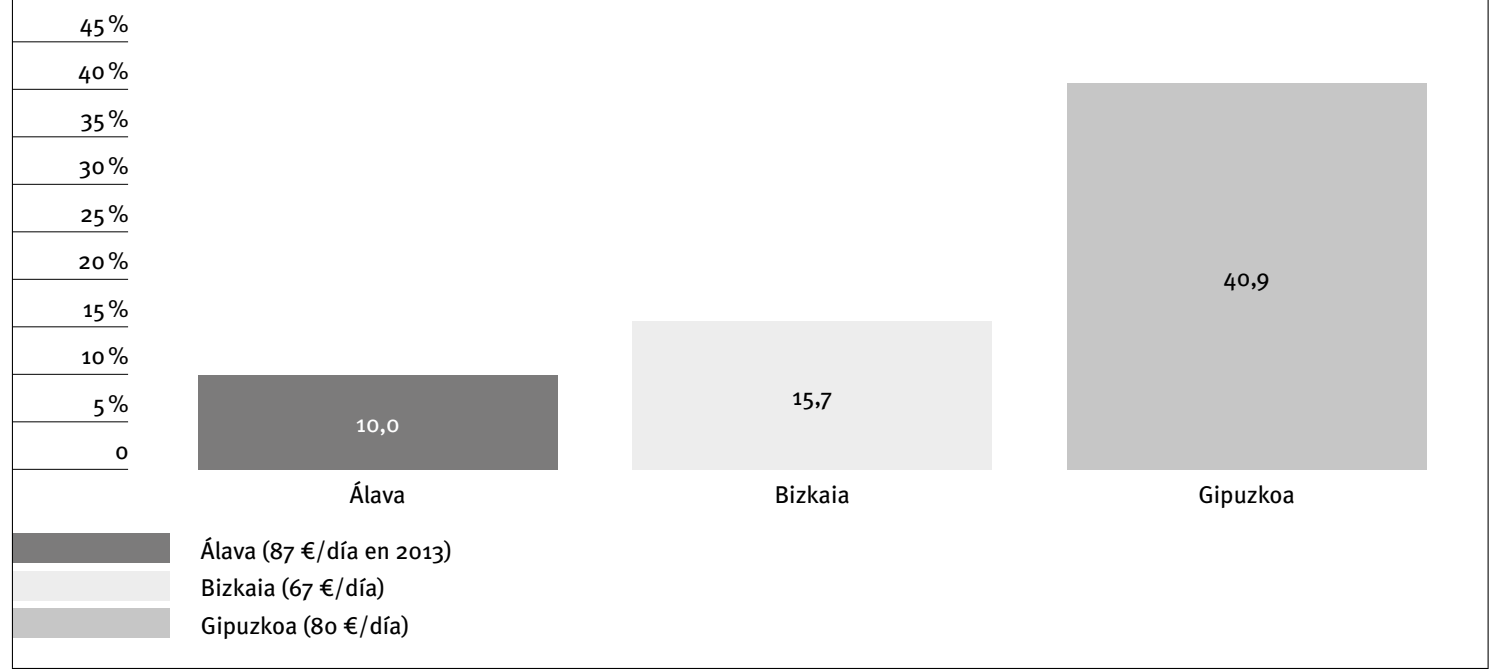

Fuentes: Estadística de Servicios Sociales y Acción Social (Órgano Estadístico Específico del Departamento de Empleo y Políticas Sociales del Gobierno Vasco) e índice de Precios de Consumo (INE).

responsabilidad pública, sino al total de las plazas existentes en nuestro territorio ${ }^{22}$. Por otra parte, también es preciso considerar que los datos hacen referencia al conjunto de servicios residenciales para personas mayores y que en ellos se incluyen, por tanto, no sólo las residencias de 15 y más plazas, sino también el resto de modalidades residenciales, como son los apartamentos tutelados y las viviendas comunitarias, que representan el $9 \%$ de la oferta total de plazas residenciales.

De lo anterior, se extrae que en Gipuzkoa el gasto corriente anual de una plaza en este tipo de centros

${ }^{22}$ Debe precisarse, en todo caso, que, al menos en el caso de Gipuzkoa la proporción de plazas enteramente privadas apenas se sitúa en el 12,3\% de la oferta residencial existente en 2013. asciende a 29.459 euros y que, a través de las cuotas, las personas usuarias abonan una media de 12.385 euros por plaza. Esto significa que la cuota media por persona usuaria ronda los 1.000 euros mensuales, que cubren en torno al $37 \%$ del coste/ plaza en centros públicos y el $46 \%$, en el caso de los centros privados. Asimismo, los datos de variación de las cuotas y el nivel de copago de las personas usuarias de servicios residenciales en Gipuzkoa, medidos en términos de euros constantes (Gráfico 14), sugieren que en los últimos doce años el ritmo de crecimiento del gasto corriente por persona usuaria (3,3\% interanual) ha sido algo mayor que el de la cuota media por persona usuaria $(2,8 \%)$, lo que ha supuesto una reducción del porcentaje de copago de dos puntos porcentuales, del $44 \%$ al $42 \%$. 


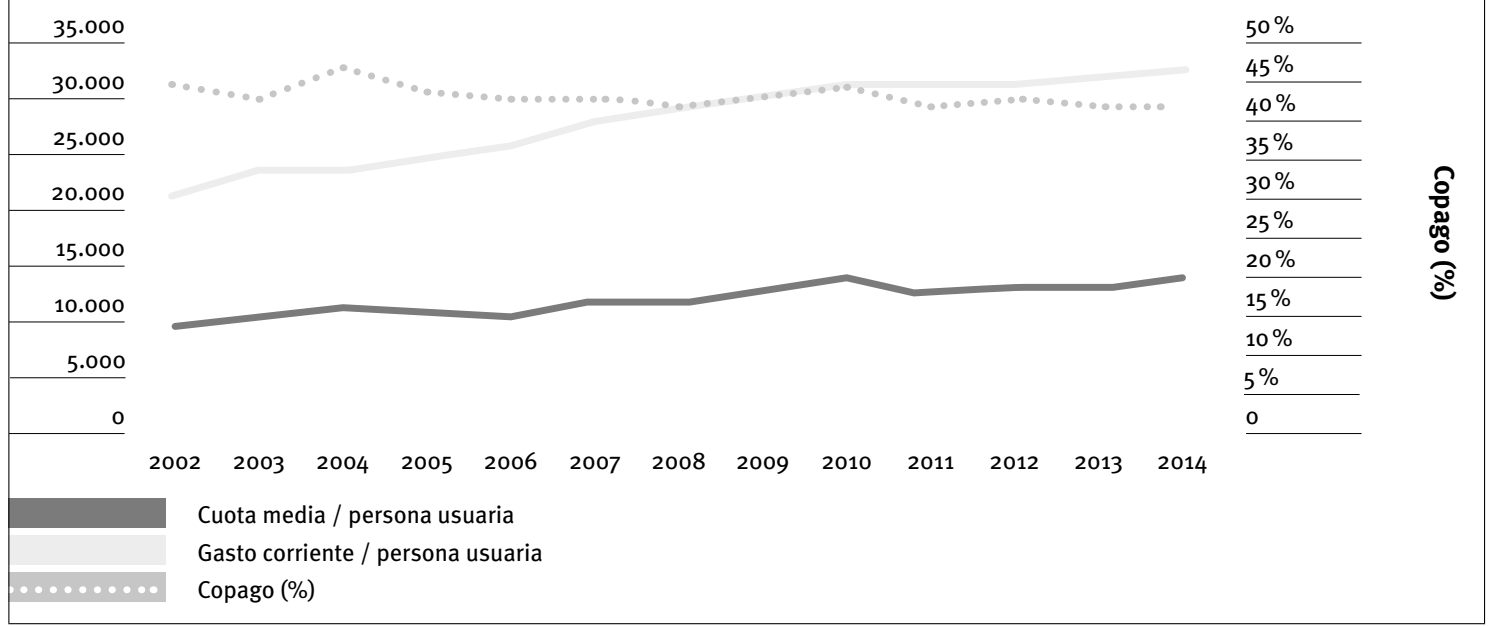

Fuente: Elaboración propia a partir de la Estadística de Servicios Sociales y Acción Social (Órgano Estadístico Específico del Departamento de Empleo y Políticas Sociales del Gobierno Vasco) y del Índice de Precios de Consumo (INE).

\subsection{Modelo de gestión y financiación}

Para terminar este apartado, se recoge la opinión de los agentes involucrados en la atención residencial en Gipuzkoa respecto al modelo de colaboración público-privada para la gestión de los servicios residenciales de responsabilidad pública y su sistema de financiación -especialmente, el copago por parte de las personas usuarias-.

\subsubsection{Modelo de colaboración público-privada en la gestión de los centros residenciales de responsabilidad pública}

Junto con la calidad de la atención, el modo en el que se articula la colaboración entre entidades privadas y Administraciones públicas en Gipuzkoa ha centrado buena parte de los debates realizados. De hecho, la mayor parte de los aspectos analizados se relacionan directa o indirectamente con la colaboración públicoprivada: la asignación de las plazas, la supervisión de los servicios, las modalidades y condiciones de la contratación de los servicios, la rentabilidad de las empresas gestoras e incluso -aunque indirectamente- las condiciones laborales en las entidades privadas.

Los datos del apartado anterior ya han puesto de manifiesto en qué medida, sin tener necesariamente más plazas o más plazas de titularidad pública que el resto de los territorios históricos de la CAPV o de las demás comunidades autónomas del Estado, el modelo residencial guipuzcoano destaca por ser el que tiene una mayor proporción de plazas concertadas y una mayor cobertura de plazas de responsabilidad pública, sumando las de titularidad foral y las concertadas con la Administración foral. Ese alto nivel de concertación y, en líneas más generales, el modelo de colaboración público-privada establecido a lo largo de los años en Gipuzkoa se considera de hecho, por parte de buena parte de las personas consultadas, una de las principales fortalezas del sistema, a juicio de una buena parte de las personas consultadas. Debe señalarse, en todo caso, que ese modelo de colaboración público-privada no es compartido necesariamente por todas las personas consultadas, algunas de las cuales consideran que el servicio residencial a las personas mayores debería ser prestado y gestionado directamente por las Administraciones públicas.

En todo caso, más allá de su validez teórica, el debate se ha centrado en el funcionamiento actual de este modelo de colaboración público-privada, tanto en lo que se refiere a las modalidades de concertación y a la asignación de las plazas como a la determinación de las condiciones en las que se ha de prestar el servicio y, por decirlo de alguna manera, al establecimiento de las reglas del juego. En lo que se refiere a este último elemento - la definición del campo de juego y la determinación de las condiciones en las que ha de prestarse el servicio-, la mayor parte de las personas consultadas ponen de manifiesto una cierta satisfacción por el papel que la Administración foral juega en cuanto a la ordenación del sector. Se valora, en este sentido, positivamente, como antes ya se ha dicho, el esfuerzo de clarificación y ordenación del modelo realizado a mediados de la pasada década y se señala como una de las fortalezas del sistema la existencia de una normativa clara, un marco de juego definido en el que se establecen las especificaciones técnicas y se actúa para garantizar que la calidad del servicio sea la adecuada.

Se plantean, en todo caso, algunas reservas en relación con el marco normativo existente -entre ellas, la obsolescencia del decreto autonómico que regula los centros residenciales (41/1998), así como el papel que, en algunos casos, la normativa actualmente vigente puede estar jugando a la hora 
de frenar el avance, la generalización de buenas prácticas y la innovación en determinados campos. También se critica el efecto que el exceso de normativas, requisitos y especificaciones técnicas puede tener a la hora de permitir el necesario grado de flexibilidad en la atención.

Es necesario también señalar que, a juicio de algunas de las personas consultadas, y como ya se ha señalado al hablar de la determinación de las condiciones laborales, el marco de colaboración público-privada construido a lo largo de los años se quebró durante la legislatura anterior a consecuencia de lo que algunas personas entienden como una excesiva injerencia en aspectos considerados propios de las entidades (básicamente, las condiciones laborales del personal ocupado, analizadas en el apartado anterior). En relación con este asunto, algunas personas insisten en la necesidad de restablecer un marco claro y estable de relación entre la Administración y las entidades privadas, que permita a éstas atenerse a un marco de juego claro y planificar a medio y largo plazo sus proyectos.

En todo caso, las críticas que se realizan en ese sentido no se limitan a actuaciones concretas desarrolladas en la pasada legislatura. El descontento que estas personas muestran por lo que consideran injerencia excesiva de la Administración en la determinación de los elementos relacionados con la gestión de las residencias se debe también a lo que consideran un mercado excesivamente intervenido, en el que se deja poco margen tanto a las empresas como a las personas usuarias. Desde este punto de vista, se pone de manifiesto una cierta insatisfacción, al menos entre algunas de las personas consultadas, en lo que se refiere al vigente modelo de concertación y de asignación de plazas de responsabilidad pública. Se critica, en este sentido, que actual modelo de concertación es rígido y que prima a las residencias concertadas a la hora de la asignación de las plazas, lo cual reduce la capacidad de elección de las personas usuarias; además, se reprueba la falta de claridad a la hora de determinar los centros con los que se conciertan las plazas residenciales. Frente a ese modelo, estas personas abogan por un sistema más flexible, en el que las personas usuarias tengan una mayor capacidad de optar entre un centro u otro. Se propone para ello, entre otras medidas, un mayor recurso a la prestación vinculada al servicio - que, como se ha señalado previamente, se ha desarrollado en muy escasa medida en nuestro territorio-.

De hecho, más allá de las modalidades concretas de concertación o contratación de los servicios, algunas de las personas consultadas abogan por una liberalización aún mayor del servicio y consideran que -junto con la acreditación, la homologación y la inspección de los centros-, las Administraciones públicas deberían limitarse a financiar el acceso a una plaza residencial a las personas que tengan derecho a ello, dejando en sus manos la elección del centro.
Desde un punto de vista más general, algunas de las personas consultadas también se muestran preocupadas por el modelo de concertación vigente, no tanto en lo que se refiere a la elección de las plazas que se conciertan con cada centro o entidad, sino en relación con el procedimiento administrativo utilizado para contratar los servicios. No hay, sin embargo, una visión unánime al respecto. Mientras que algunas personas señalan su desacuerdo con la preeminencia que la Ley de Servicios Sociales (5/1996) da a las entidades sin fin de lucro a la hora de la concertación de los servicios sociales de responsabilidad pública, otras critican la falta de desarrollo del modelo específico de concertación que esa ley establece. Algunas de las personas consultadas también ponen de relieve que, a medio y largo plazo, el sistema de concertación va a tener que ir siendo sustituido por un modelo de concurso público, más ajustado a los requerimientos europeos en materia de competencia y libre concurrencia en la contratación pública. Ello tendrá, a su juicio, unas consecuencias claras sobre la actual situación, y muchas de las entidades que en la actualidad gestionan centros residenciales bajo la figura del convenio tendrán que concursar con otras entidades para poder seguir gestionado las plazas de responsabilidad foral.

Otra de las cuestiones relevantes en lo que se refiere al modelo de colaboración público-privada -más allá de la cuestión de la financiación de las plazas de atención, que se aborda posteriormente- es la relativa a la homologación, acreditación, inspección y evaluación del servicio prestado en los centros. No puede decirse que haya un consenso claro a la hora de valorar la situación a este respecto. Para algunas personas, el modelo de inspección foral es el adecuado y cumple con su objetivo de garantizar la calidad de la atención. Para otras, en cambio, es mejorable, en la medida en que si bien garantiza el cumplimiento de ciertos requerimientos formales, no permite garantizar una adecuada calidad de la atención, sobre todo si ésta se entiende desde una perspectiva integral.

\subsubsection{Financiación de la atención residencial y participación económica de las personas usuarias}

La cuestión de la financiación de la atención residencial pública está estrechamente relacionada con algunos de los elementos que ya se han ido analizando -fundamentalmente, la colaboración público-privada y las fórmulas establecidas para la concertación de plazas, aunque también, indirectamente, las condiciones laborales del personal-, y ha sido, por tanto, parcialmente abordada en las páginas precedentes. En este apartado se analizan, en todo caso, con mayor detalle las tres cuestiones que, a lo largo de los debates, se han planteado sobre la financiación de los centros residenciales: el establecimiento de las tarifas de concertación (y su relación con la viabilidad económica de las empresas o entidades gestoras), 
la participación económica de las personas usuarias en la financiación del servicio, y la sostenibilidad a medio y largo plazo del modelo de atención residencial (y del modelo actual de servicios sociales en general).

Desde un punto de vista cualitativo, en lo que se refiere al sistema de tarificación establecido, se considera válida, en general, la aplicación de un modelo de tarificación que distinga las necesidades de las personas usuarias en función de la carga asistencial que suponen. Sobre esta cuestión, algunas personas plantean en todo caso la necesidad de actualizar los sistemas de asignación de perfiles de dependencia y, en consecuencia, del sistema de financiación requerido por cada residencia en función de su case-mix de usuarios. A su juicio el modelo actual obliga a realizar ajustes presupuestarios internos de cada organización entre diferentes partidas para garantizar la financiación de las necesidades reales de plantillas de personal, favorece la despreocupación por realizar valoraciones del nivel de dependencia, porque no suponen cambio alguno en el módulo de financiación (lo que dificulta plantearse como metodología asistencial la atención centrada en la persona), y provoca una distribución descompensada de perfiles por geriátricos (sin correlación consistente entre dotaciones de personal e índices de case-mix), lo que cuestiona la gestión de las listas de espera y su incidencia en la realidad asistencial de cada centro.

En un sentido similar, algunas de las personas consultadas plantean la necesidad de que la tarifa de concertación establecida contemple variables adicionales a las que ahora se tienen en cuanta, así como la posibilidad de aplicar en la tarifa variables relativas al cumplimiento de los requerimientos y objetivos establecidos. También se plantea la necesidad de reconocer de algún modo la distribución arquitectónica de los centros a la hora de establecer las tarifas de concertación.

Más allá de la forma en la que se establecen la tarifas, algunas de las personas consultadas reflexionan también sobre la propia cuantía de la tarifa y su relación con la viabilidad económica de los centros concertados con la Administración foral, en un contexto en el que el coste/plaza ha crecido debido a la ya señalada mejora de las condiciones salariales. En ese sentido, señalan que los costes crecen en mayor medida que las tarifas de concertación, y que las mejoras salariales introducidas en los últimos años han tenido un efecto claro en la viabilidad económica de los centros, de forma que el déficit de los centros concertados ronda cada año entre el $2 \%$ y el $3 \%$ de los gastos totales.

Los datos disponibles indican, en cualquier caso, dos elementos de importancia relativos a las tarifas de concertación. Por una parte, puede decirse que el coste/plaza y la tarifa fijada a los centros han evolucionado de forma similar, cubriendo la tarifa, dependiendo de los años, entre el $90 \%$ y el $100 \%$ del coste/plaza ${ }^{23}$. En ese sentido, tanto el coste/plaza de este tipo de centros como la tarifa de concertación han crecido entre 2004 y 2013 en torno a un $67 \%$. Cabe añadir que, entre 2013 y 2015 , la tarifa creció en un $3 \%$ adicional, hasta los 90,5 euros diarios (en el caso analizado, que corresponde a las plazas para personas dependientes aplicable a entidades exentas de IVA).

Gráfico 15. Evolución del precio de concertación y del gasto corriente/plaza en servicios residenciales para personas mayores. Gipuzkoa, 2002-2014 (euros/día)

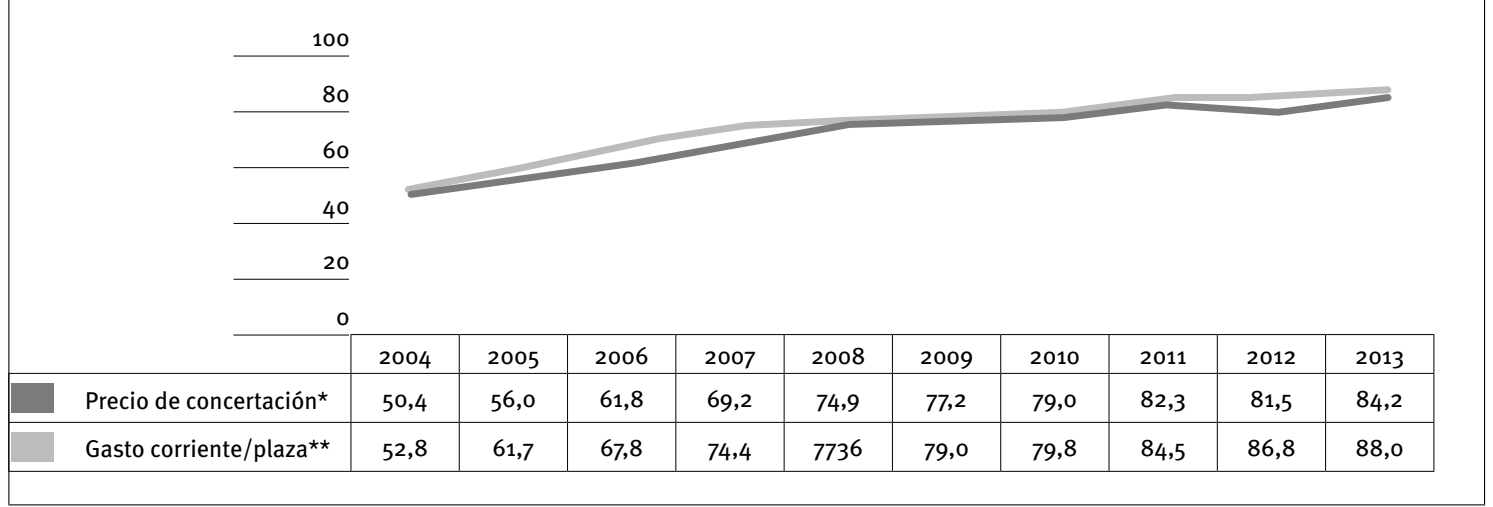

* Precio de concertación (en euros por día) que la Diputación Foral de Gipuzkoa abona a entidades exentas de IVA para la atención residencial de personas dependientes (grados II y III). ** Gasto corriente/plaza (en euros por día) promedio de los centros residenciales de personas mayores dirigidos a personas dependientes y mixtos.

Fuente: Estadística de Servicios Sociales y Acción Social (Órgano Estadístico Específico del Departamento de Empleo y Políticas Sociales del Gobierno Vasco).

${ }^{23}$ Este cálculo deriva de comparar la evolución de la tarifa que la Diputación abona por cada plaza para personas con grado II o III de dependencia y el coste/plaza correspondiente, de acuerdo con la Estadística de Servicios Sociales, a las plazas para personas dependientes en los centros residenciales guipuzcoanos. 
Tabla 1. Tarifas de concertación establecidas, por comunidades autónomas y tipo de plaza. Estado español, 2015 (euros/día)

\begin{tabular}{|c|c|c|c|c|}
\hline & Grado I & Grado II & Grado III & Psicogeriátricas \\
\hline Andalucía & \multicolumn{3}{|c|}{$51,70^{1}$} & $64,30^{2}$ \\
\hline Aragón & \multicolumn{3}{|c|}{48,80} & $75,80^{3}$ \\
\hline Asturias & \multicolumn{3}{|c|}{48,80} & \\
\hline Baleares & \multicolumn{3}{|c|}{$64,00-68,00^{4}$} & \\
\hline Canarias & \multicolumn{3}{|c|}{$41,00-56,00^{5}$} & \\
\hline Cantabria & & 46,70 & & 46,74 \\
\hline Castilla y León & $30,72^{6}$ & $43,00^{7}$ & $30,72^{8}$ & $43,00^{9}$ \\
\hline Castilla-La Mancha & 40,77 & 48,55 & 40,77 & 48,55 \\
\hline Cataluña & \multicolumn{3}{|c|}{56,16} & \\
\hline Álava & \multicolumn{3}{|c|}{$50,00-56,60^{10}$} & \\
\hline Bizkaia & \multicolumn{3}{|c|}{$81,00^{11}$} & \\
\hline Gipuzkoa $^{12}$ & 70,23 & \multicolumn{2}{|c|}{88,03} & 94,99 \\
\hline Extremadura & \multicolumn{3}{|c|}{40,00} & \\
\hline Galicia & \multicolumn{3}{|c|}{$46,55^{13}$} & \\
\hline Comunidad de Madrid & \multicolumn{3}{|c|}{50,14} & \\
\hline Región de Murcia & \multicolumn{3}{|c|}{50,30} & \\
\hline Navarra & \multicolumn{3}{|c|}{$56,60-70,00^{14}$} & \\
\hline La Rioja & & 27,00 & & 27,00 \\
\hline Comunidad Valenciana & \multicolumn{3}{|c|}{51,00} & \\
\hline
\end{tabular}

(1) Personas mayores con dependencia. (2) Personas mayores con trastornos graves o continuados de conducta. (3) Personas con alteraciones de conducta. (4) En función del grado de dependencia. (5) En función de la institución financiadora. (6) Persona autónomas. (7) Personas con dependencia. (8) Persona autónomas. (9) Personas con dependencia. (10) En función del grado de dependencia. (11) Asistida. (12) Entidades no exentas de IVA. (13) Por término medio, en función de diversos tipos de perfiles. (14) En función del grado de dependencia.

Fuente: Elaboración propia a partir del V Mapa Lares (2015).

Por otra parte, debe destacarse que, de acuerdo con los datos recogidos en la Tabla 1 -extraídos del $\checkmark$ Mapa Lares, elaborado en octubre de 2015Gipuzkoa es, con diferencia, el territorio del Estado que abona tarifas de concertación más elevadas. En efecto, las tarifas guipuzcoanas son superiores a las de Álava o Navarra, y se alejan significativamente de las que se abonan en comunidades con el mismo nivel de renta que Gipuzkoa, como Cataluña o Madrid.

Analizada la cuestión de la financiación pública de las residencias, se han planteado también en los debates algunas consideraciones de interés relativas a la participación económica de las personas usuarias en la financiación de los servicios que reciben $^{24}$. En general, las personas consultadas no cuestionan la idea del copago, aunque sí plantan una serie de consideraciones sobre dos aspectos concretos: por un lado, el modo en el que debe ser considerado el patrimonio, mobiliario e inmobiliario, de las personas residentes a la hora de establecer el precio público que deben abonar; por otro, el

${ }^{24}$ Como se ha señalado previamente, las personas usuarias se hacen cargo a través del copago, por término medio, de en torno a un $42 \%$ del gasto corriente que implica la ocupación de una plaza residencial. propio modelo de copago y el tipo de gastos que se deberían tener en cuenta para su determinación.

Una de las cuestiones que se señalan en relación con el copago se refiere al efecto que tiene a la hora de retraer la demanda, especialmente de personas con cierto grado de renta o patrimonio, en la medida en que les resulta más rentable seguir en su domicilio - o volver a él-y percibir la prestación económica para el cuidado en el entorno familiar, contratando, en su caso, a una persona que se encargue de los cuidados. Se insiste en ese sentido que -salvo en los casos en los que las necesidades son muy intensas o las posibilidades de cuidado muy limitadas - las familias analizan las opciones disponibles y concluyen que, desde el punto de vista económico, el ingreso en residencia puede no ser la opción más ventajosa.

En lo que se refiere a la consideración del patrimonio, se plantean posiciones divergentes. Algunas personas opinan que no debería tenerse en cuenta para el cálculo de la aportación económica, en la medida en que desincentiva el ahorro o penaliza a quienes han sido capaces de un cierto patrimonio a lo largo de los años. También se señala que la consideración del patrimonio aleja del sistema público de cuidados a las personas que cuentan 
con cierto nivel patrimonial, que encuentran en los servicios domiciliarios privados, en ocasiones en el marco de la economía sumergida, una alternativa más barata al ingreso residencial. Por el contrario, otras personas lo que critican es que no se tenga en cuenta la vivienda habitual a la hora del cálculo de la aportación económica, y proponen recuperar la figura del reconocimiento de deuda, computando el valor de todo el patrimonio, incluyendo la vivienda habitual.

Más allá de la consideración del patrimonio, surge también el debate sobre si -como ocurre en otros países y se ha propuesto en nuestro entorno $0^{25}$ - debería establecerse un sistema de triple tarificación, mediante el cual se distinga, a la hora del copago, entre los costes hoteleros, los de salud y los relativos a la atención social o a la dependencia. En los sistemas en los que existe esa triple tarificación, la atención sanitaria es financiada por la Administración de salud, y no se tiene en cuenta para la determinación del copago. Algo similar ocurre con los cuidados asistenciales derivados de la dependencia, que son financiados en todo o en parte por el sistema de atención social. El copago se refiere, por tanto, fundamentalmente a los aspectos hoteleros, que financia íntegramente la persona usuaria (y el correspondiente sistema de garantía de ingresos, en el caso de que carezca de ingresos suficiente para abonar esas cantidades). La idea de esta triple tarificación parece, en general, adecuada para las personas consultadas, al menos en términos de equidad, si bien se señala que - dado el escaso peso en relación con el coste real tienen los aspectos hoteleros-implicaría necesariamente un incremento muy sustancial del gasto público dedicado a financiar estos servicios, y una presión impositiva mayor.

Por último, en alguno de los grupos de discusión se plantea una reflexión más generalizada sobre la sostenibilidad del sistema de servicios sociales y sobre las posibilidades que puedan existir para garantizarla. Se hace referencia, en ese sentido, a la

${ }^{25}$ La propia Ley de Dependencia establece (art. 33) que, para fijar la participación del beneficiario, se tendrá en cuenta la distinción entre servicios asistenciales, y de manutención y hoteleros. A la hora de explicar la lógica de esta recomendación, el Informe final del grupo de expertos para la evaluación del desarrollo y efectiva aplicación de la Ley 39/2006 señalaba, en 2009, que el copago debería aplicarse "fundamentalmente para contingencias que no estuvieran en el 'núcleo' de las prestaciones de dependencia o que, estándolo, no tuviesen alternativas o complementos. Hay que admitir, sin embargo, que la definición del núcleo es complicada: si éste es demasiado amplio, el copago no sería muy efectivo. Los cuidados sanitarios, dentro de un caso de dependencia, no deberían estar sometidos a copago, al menos mientras la sanidad en sentido estricto no lo esté tampoco. Los servicios complementarios (fuera del núcleo en cualquier caso, y quizás otros) ya están, por lo general, cubiertos por el propio beneficiario, salvo en casos de carencia de recursos. Los servicios del módulo hotelero, salvo en caso de carencia de recursos (establecida en función de la renta, cuando el patrimonio sea difícil de estimar), sí deberían ser objeto de copago [...]. El sistema de copago debe articularse progresivamente desde el punto de vista funcional, mediante círculos concéntricos de servicios en lo que se refiere a su intensidad, que vaya de más copago para servicios asociados a la dependencia pero fuera del núcleo hacia menos copago a medida que los servicios aludidos se sitúan en el centro de las prestaciones de dependencia” (Cervera Macià et al., 2009: 21, 56). posibilidad - como se hace en otros países y se ha propuesto para Euskadi y para el Estado españolde afectar algún impuesto o crear una cotización específica para la cobertura de los gastos vinculados a la dependencia o al envejecimiento.

\section{Fortalezas y debilidades}

Se recogen finalmente las principales conclusiones que se derivan, en relación con las fortalezas y las debilidades de la red de atención residencial a las personas mayores en Gipuzkoa, del análisis realizado en los apartados anteriores. Se recogen en ese sentido los aspectos que, a juicio de los redactores del informe, resultan más significativos a la luz de los datos cuantitativos disponibles y de las opiniones recogidas durante el proceso de reflexión. Es importante señalar que este diagnóstico no es necesariamente compartido por todas las personas que han participado en el proceso, ni por el Departamento de Políticas Sociales de la Diputación Foral de Gipuzkoa, sino que recoge únicamente las cuestiones que los redactores del informe consideran más relevantes y significativas para explicar la situación de la red de centros residenciales.

Entre las fortalezas, cabría destacar las siguientes:

- La primera fortaleza consiste en la existencia de un marco político y legislativo avanzado, que garantiza como derecho subjetivo una atención residencial de suficiente calidad a todas las personas en situación de necesidad, siempre que cumplan los requisitos de acceso establecidos. Ese derecho se garantiza además independientemente del nivel de recursos económicos de la persona usuaria y, en líneas generales, independientemente de su lugar de residencia.

- Cabe considerar también como una fortaleza la existencia de una dotación de plazas de responsabilidad pública - plazas públicas y privadas concertadas- más elevada que en la mayor parte de los territorios de nuestro entorno, con una distribución territorial que, pese a sus carencias, es razonablemente buena y equilibrada. En ese sentido, y pese al incremento en las listas y en los plazos de espera, parece claro que -especialmente en los casos de mayor urgencia- el ingreso en los centros residenciales se realiza con rapidez y que todas las personas demandantes acceden en un plazo razonable a la plaza solicitada.

- Pese a la existencia de perspectivas diferentes en relación con esta cuestión, es necesario destacar también la existencia en Gipuzkoa de un marco de colaboración público-privada razonablemente sólido y ordenado, que constituye la base del modelo guipuzcoano de servicios sociales y garantiza unos resultados objetivamente buenos desde el punto de vista de la dotación de plazas, la calidad de la atención, el equilibrio territorial 
e, incluso, una cierta equiparación en cuanto a las condiciones laborales del personal, así como unos resultados positivos en términos de coste-efectividad.

- Cabe también considerar como una fortaleza del modelo, de acuerdo con la mayor parte de las personas consultadas, la calidad de la atención que se presta en el conjunto de los centros residenciales y el avance que progresivamente se está produciendo hacia una atención más individualizada e integral, en la línea del modelo de atención centrado en la persona. Si bien no cabe duda de que, como se indica al señalar las debilidades del modelo, es necesario todavía dar más pasos en este aspecto -tanto desde el punto de vista práctico como de la asunción teórica de ese tipo de modelos-, no puede dejar de indicarse el nivel de profesionalidad que caracteriza al conjunto de los centros de la red y la garantía de unos mínimos asistenciales básicos. Ese elevado nivel de calidad se deriva, en parte, de la existencia de ratios de atención, perfiles profesionales y prestaciones técnicas superiores a los que exigen las normativas estatal y autonómica, a partir del proceso de ordenación y clarificación del modelo de atención a las personas mayores realizado a mediados de la pasada década.

- También debe destacarse como una de las fortalezas básicas del sector el proceso de mejora de las condiciones laborales que se ha ido desarrollando a lo largo de los últimos años y que ha conseguido, objetivamente, dignificar las condiciones laborales en el sector y garantizar a todo el personal ocupado -independientemente de la titularidad del centro- unas condiciones laborales razonables, equiparándose en gran medida a otros sectores de la economía guipuzcoana (en cuanto a salarios, horarios, derechos a la conciliación).

- En relación con las condiciones laborales, debe destacarse también la creciente capacidad del sector para la creación de empleo -empleo además, como hemos visto, de cierta calidady su elevada rentabilidad social, tanto desde el punto de vista de la respuesta a las necesidades atendidas como desde el punto de vista del retorno que el gasto realizado tiene para las arcas públicas, mediante el incremento de las cotizaciones y la recaudación por IRPF y otros impuestos.

- Cabe indicar finalmente, como otra de las fortalezas del sistema, la voluntad política y social que existe en el territorio para mantener un nivel importante de gasto público en este sector, que ha permitido combinar en los últimos años diversos objetivos -incremento de plazas, mejora de las condiciones laborales, mejora de la calidad de la atención-, garantizando a las entidades concertadas un nivel de financiación, mediante la tarifa de concertación, más elevado que en otros territorios de nuestro entorno.
En sentido contrario, las principales debilidades de la red de atención residencial a las personas mayores serían las siguientes:

- Todos los agentes consultados coinciden en que se ha producido un cambio importante en el perfil de las personas usuarias, que son cada vez más mayores, con mayor grado de dependencia y con necesidades sociosanitarias más intensas. Cabe también hablar de un cierto cambio cultural en las expectativas de las personas usuarias y de sus familias, en su nivel de exigencia y en la concepción de la residencia como derecho social, y no como ayuda de beneficencia. Estas modificaciones sólo en parte se han acompañado, sin embargo, de la necesaria adaptación del modelo de atención, tanto en lo que se refiere a las prestaciones técnicas, los perfiles profesionales y las ratios de atención como a las instalaciones y los ambientes de las residencias. Desde ese punto de vista, parece clara la necesidad de revisar y actualizar el modelo de atención, adaptándolo a esos nuevos perfiles y reforzando, frente a la tendencia a la medicalización de los centros, los elementos más ligados a la intervención psicosocial y sociocultural.

- También debe indicarse como una debilidad las dificultades para avanzar en el desarrollo de modelos de atención suficientemente individualizada, y de ambientes e instalaciones más hogareños. La necesidad de mejorar la calidad de la atención, si bien se extiende al conjunto de la red, es particularmente clara en el caso de las personas con trastornos psiquiátricos y psicogeriátricos y, en general, de las personas con problemas complejos.

- Otra de las debilidades del modelo es la persistencia de prejuicios culturales frente a la institución residencial, que se traduce en un cierto estigma asociado al ingreso en una residencia y en dificultades para materializar la 'demanda oculta'. Esa demanda oculta estaría formada por todas aquellas personas que no demandan, por distintas causas, un ingreso residencial, pero que muy probablemente tendrían una mejor calidad de vida si accedieran en el momento adecuado a un plaza en una residencia. En ese sentido, los debates realizados han puesto de manifiesto que, si bien el mantenimiento en el domicilio ha de seguir considerándose como el principal objetivo de las políticas de atención a las personas mayores, debe cuestionarse la idea de que el domicilio es siempre y en todo caso la mejor opción para todas las personas mayores. Desde ese punto de vista, es necesaria una labor importante para hacer de la opción residencial una alternativa más atractiva, sensibilizando a las personas potencialmente demandantes y adecuando las pautas asistenciales, organizativas y de financiación de estos centros.

- Si bien previamente se ha indicado, entre las fortalezas del sistema, que existe una dotación razonablemente buena de plazas y un equilibrio 
territorial también razonable, no puede dejar de señalarse -entre las debilidades- el incremento de las listas de espera y, sobre todo, las dificultades para crear nuevas plazas y, al menos, mantener las actuales tasas de cobertura. Desde ese punto de vista, parece obvia la necesidad de acelerar el ritmo de creación de nuevas plazas de responsabilidad pública, que den respuesta al incremento de la población potencialmente demandante y al ya señalado crecimiento de la demanda de plazas.

- En lo que se refiere a los aspectos estrictamente económicos, cabe considerar como una debilidad que el incremento del gasto público y privado que se ha experimentado en los últimos años se haya derivado básicamente del incremento del coste/plaza -derivado, a su vez, de la mejora de las remuneraciones-, y no tanto de la creación de nuevas plazas. Junto con este elemento, también cabría señalar que esos incrementos no han conseguido reducir por completo las desigualdades que se producen en las condiciones laborales del personal, en función tanto de la titularidad de los centros (pública o privada) como del tipo de vinculación laboral (trabajadores/as propios o subcontratados) o la fórmula de gestión (directa o indirecta).

- Asimismo, se pone también de manifiesto la persistencia de diferencias en las condiciones laborales del personal, dependiendo tanto del tipo de contratación - personal propio o subcontratado-y de la titularidad del centro - público o privado- como del modelo de gestión -directa o indirecta-. Si bien es cierto que las diferencias han tendido a reducirse en los últimos años, siguen siendo muy notables tanto desde el punto de vista salarial como desde otras perspectivas. Se señala, en ese sentido, que la falta de un convenio sectorial y el hecho de que se hayan multiplicado los convenios de empresa provoca distorsiones que se acentúan en función de la forma de contratación del personal.

- Por otra parte, a la hora de analizar las debilidades relativas al modelo de colaboración público-privada, es necesario hacer referencia a la tensión que se observa entre dos lógicas contrapuestas: una lógica de servicio público, por una parte, frente a una lógica de actividad comercial convencional por otra, sujeta a la libre concurrencia entre empresas y a la libertad de elección de las personas usuarias, consideradas como clientes o consumidoras de un servicio determinado. La existencia de esas dos lógicas -y la necesidad de responder a ambas- hace que se planteen soluciones y medidas muy diferentes, en ocasiones contradictorias, para los mismos problemas; y obliga, en todo caso, a conciliar elementos relacionados con la garantía del servicio público y con una perspectiva más 'consumista' o mercantil del servicio (en lo que se refiere, por ejemplo, a la liberalización del mercado, o a los mecanismos de asignación y concertación de las plazas). Vinculado a esa tensión entre las dos lógicas señaladas, cabe hacer también referencia a una cierta crisis cabe pensar que coyuntural- en el modelo de colaboración público-privada establecido hasta ahora, que se ha traducido en una sensación de inestabilidad y de injerencia entre una parte de los agentes implicados.

- Relacionada con lo anterior, cabe considerar como una debilidad del sector el mayor riesgo de conflictividad laboral, en un contexto en el que la diversidad de agentes implicados (instituciones, personas usuarias, entidades, personal ocupado en diversas redes) es amplia, con intereses, referentes y capacidades de presión muy diferentes.

- Cabe indicar finalmente, como una de las principales debilidades del sistema, el riesgo de insostenibilidad económica del modelo en su conjunto, en ausencia de crecimiento económico y de voluntad política y social para revisar la financiación del Estado de bienestar. En este sentido, se plantea la necesidad de reorientar el modelo de financiación de las residencias y, en general, de las políticas sociales asociadas al envejecimiento, mediante la modificación de la participación económica de las personas usuarias o la introducción de mecanismos de financiación adicional. Ello requeriría un debate más amplio sobre el grado de mutualización del riesgo de dependencia que está dispuesto a asumir la sociedad guipuzcoana. 
CASTILLA Y LEÓN (2016): “Decreto 2/2016, de 4 de febrero, de autorización y funcionamiento de los centros de carácter social para la atención a las personas mayores en Castilla y León", Boletín Oficial de Castilla y León, $\mathrm{n}-24$, 5-2-16, págs. 5.942-5.981 [khttp://bocyl.jcyl.es/html/2016/02/05/html/ BOCYL-D-05022016-2.do>].

CERVERA MACIÀ, M. et al. (2009): Informe final del grupo de expertos para la evaluación del desarrollo y efectiva aplicación de la Ley 39/2006, 14 de diciembre, de Promoción de la Autonomía Personal y Atención a las Personas en Situación de Dependencia, Imserso [<http://riberdis. cedd.net/handle/11181/3379'].

DIPUTACIÓN FORAL DE GIPUZKOA (2005): Modelo de atención a las personas mayores dependientes en Gipuzkoa. Propuesta para el debate político. Octubre 2005, Diputación Foral de Gipuzkoa, Donostia-San Sebastián [<http://www.siis.net/ es/documentacion/catalogo/Record/136758>].

DIPUTACIÓN FORAL DE GIPUZKOA. DEPARTAMENTO DE POLÍTICAS SOCIALES (2015): Cartera de servicios. Anexo 2015. Datos básicos oferta, San Sebastián, Departamento de Políticas Sociales [rhttp://www.behagi.eus/files/informes/ cartera.servicios.2015.pdf)].

DIPUTACIÓN FORAL DE GIPUZKOA. DEPARTAMENTO PARA LA POLÍTICA SOCIAL (2006): Catálogo de servicios residenciales para personas mayores / Adineko pertsonentzako egoitza zerbitzuen katalogoa, Donostia-San Sebastián, Diputación Foral de Gipuzkoa [<http://www.siis.net/es/ documentacion/catalogo/Record/1415411].

ESPAÑA (2006): “Ley 39/2006, de 14 de diciembre, de Promoción de la Autonomía Personal y Atención a las Personas en Situación de Dependencia", Boletín Oficial del Estado, n-299, 15-12-6, págs. 44.142-44.156 [ [http://www.boe.es/ buscar/doc.php?id=BOE-A-2006-21990〉].
FEDERACIÓN DE RESIDENCIAS Y SERVICIOS DE ATENCIÓN A LOS MAYORES-SECTOR SOLIDARIO [LARES] (2015): V Mapa Lares, Federación de Residencias y Servicios de Atención a los Mayores-Sector Solidario [<http://www. laresfederacion.org/images/pdf/archivos/ Mapa\%2oLares\%202015.pdf〉].

PAÍS VASCO (2015): “Decreto 185/2015, de 6 de octubre, de Cartera de Prestaciones y Servicios del Sistema Vasco de Servicios Sociales", Boletín Oficial del País Vasco, no 206, 29-10-15, págs. 1-87 [khttps://www.euskadi.eus/y22-bopv/es/ bopv2/datos/2015/10/1504561a.shtml>].

- (2013): “Decreto 353/2013, de 28 de mayo, de Ficha Social del Sistema Vasco de Servicios Sociales y del Instrumento de Diagnóstico Social del Sistema Vasco de Servicios Sociales", Boletín Oficial del País Vasco, no 121, 26-6-13 [rhttps:// www.euskadi.eus/y22-bopv/es/bopv2/ datos/2013/06/1302907a.shtmls].

- (1998): “Decreto 41/1998, de 10 de marzo, sobre los servicios sociales residenciales para la tercera edad", Boletín Oficial del País Vasco, no 66, 7-4-98, págs. 5.973-5.993 [<https:// www.euskadi.eus/y22-bopv/es/bopv2/ datos/1998/04/9801505a.shtmls].

- (1996): “Ley de Servicios Sociales 5/1996", Boletín Oficial del País Vasco, no 218, 12-11-96, págs. 17.57817.599 [rhttps://www.euskadi.eus/y22-bopv/ es/bopv2/datos/1996/11/9605350a.shtml)].

SIIS CENTRO DE DOCUMENTACIÓN Y ESTUDIOS (2016): La situación de los centros residenciales para personas mayores en Gipuzkoa, Donostia-San Sebastián, SIIS Centro de Documentación y Estudios. 
BEHAGI-OBSERVATORIO SOCIAL DE GIPUZKOA [khttp:// behagi.eus>].

CONSEJO SUPERIOR DE INVESTIGACIONES CIENTÍFICAS

(2013): Estadísticas sobre residencias (distribución de centros y plazas residenciales por provincia).

DEPARTAMENTO DE ACCIÓN SOCIAL DE LA DIPUTACIÓN FORAL DE BIZKAIA (2015) [datos internos].

DEPARTAMENTO DE POLÍTICAS SOCIALES DE LA DIPUTACIÓN FORAL DE GIPUZKOA (2015) [datos internos].

DEPARTAMENTO DE SERVICIOS SOCIALES DE LA DIPUTACIÓN FORAL DE ÁLAVA (2015) [datos internos].
EUSTAT (2013): Población en Relación con la Actividad.

INSTITUTO NACIONAL DE ESTADÍSTICA (2008-2014): Encuesta Anual de Coste Laboral.

- (2002-2014): Índice de Precios de Consumo.

MINISTERIO DE EMPLEO Y SEGURIDAD SOCIAL (2002-2014): Afiliación de Trabajadores a la Seguridad Social.

ÓRGANO ESTADÍSTICO ESPECÍFICO DEL DEPARTAMENTO DE EMPLEO Y POLÍTICAS SOCIALES DEL GOBIERNO VASCO (1994-2014 [avance]): Estadística de Servicios Sociales y Acción Social. 